Article

\title{
Study of the Direct Red 81 Dye/Copper(II)-Phenanthroline System
}

\author{
Elsa Walger ${ }^{1, *}$, Nathalie Marlin ${ }^{1}$, Florian Molton ${ }^{2}$ (D) and Gérard Mortha ${ }^{1}$ \\ 1 Univ. Grenoble Alpes, CNRS, Grenoble INP, LGP2, 461 rue de la Papeterie-CS 10065, \\ 38402 Saint Martin d'Hères Cedex, F-38000 Grenoble, France; \\ nathalie.marlin@pagora.grenoble-inp.fr (N.M.); gerard.mortha@pagora.grenoble-inp.fr (G.M.) \\ 2 Univ. Grenoble Alpes, CNRS, DCM, CS 40700, 38058 Grenoble Cedex 9, F-38000 Grenoble, France; \\ florian.molton@univ-grenoble-alpes.fr \\ * Correspondence: elsa.walger@lgp2.grenoble-inp.fr; Tel.: +33-476-826-943
}

Received: 7 December 2017; Accepted: 16 January 2018; Published: 25 January 2018

\begin{abstract}
Recovered papers contain several chromophores, such as wood lignin and dyes. These have to be eliminated during paper recycling in order to produce white paper. Hydrogen peroxide under alkaline conditions is generally used to decolorize lignin, but its effect on dyes is limited. Copper(II)-phenanthroline (Cu-Phen) complexes can activate the oxidation of lignin by hydrogen peroxide. Hydrogen peroxide may also be activated during recycled fiber bleaching, thus enhancing its color-stripping efficiency towards unoxidizable azo dyes. The purpose of this paper was to determine the effect of $\mathrm{Cu}$-Phen complexes on a model azo dye, Direct Red 81 (DR81), in aqueous solution. Different Cu-Phen solutions (with different initial Cu:Phen molar ratios) were prepared and mixed with the dye at different $\mathrm{pHs}$. The geochemical computer program PHREEQC allowed precise calculation of the theoretical distribution between different possible coordinates $\left(\mathrm{CuPhenOH}^{+}\right.$, $\mathrm{Cu}$ (Phen $)_{2}{ }^{2+}, \mathrm{CuPhen}(\mathrm{OH})_{2}, \mathrm{Cu}(\mathrm{Phen})_{3}{ }^{2+}$, etc.) depending on $\mathrm{pH}$ and initial concentrations. UV-vis spectroscopic measurements were correlated with the major species theoretically present in each condition. The UV absorbance of the system was mainly attributed to the Cu-Phen complex and the visible absorbance was only due to the dye. Cu-Phen appeared to reduce the color intensity of the DR81 dye aqueous solution under specific conditions (more effective at $\mathrm{pH} 10.7$ with Cu:Phen = 1:1), probably owing to the occurrence of a coordination phenomenon between DR81 and $\mathrm{Cu}$-Phen. Hence, the ligand competition between phenanthroline and hydroxide ions would be disturbed by a third competitor, which is the dye molecule. Further investigation proved that the DR81 dye is able to form a complex with copper-phenanthroline, leading to partial color-stripping. This new "color-stripping effect" may be a new opportunity in paper and textile industries for wastewater treatment.
\end{abstract}

Keywords: Direct Red 81 azo dye; copper(II)-phenanthroline; UV-vis spectroscopy; coordination; EPR spectroscopy; speciation simulation; color-stripping

\section{Introduction}

Dyes are commonly used in paper manufacturing as additives to produce colored papers. They absorb the visible light because of their highly conjugated structures, which contain several groups with $\pi$-electron clouds, such as azo groups, ethylene groups, carbonyl groups and aromatic rings. When combined, these structures constitute the chromophore part of the molecule. The auxochrome groups provide the other properties of the dye: solubility, charge, and affinity to cellulose. These are amine, hydroxyl, sulfonic or carboxyl groups.

Direct dyes have a good affinity with both bleached and unbleached chemical pulps. They represent more than half of the dyes present in the pulp and textile industries [1] and they 
usually contain at least one azo group and some sulfonic acid groups thus making them soluble. Most dyes used in the industry are azo dyes, such as the Direct Red 81 dye (Figure 1).

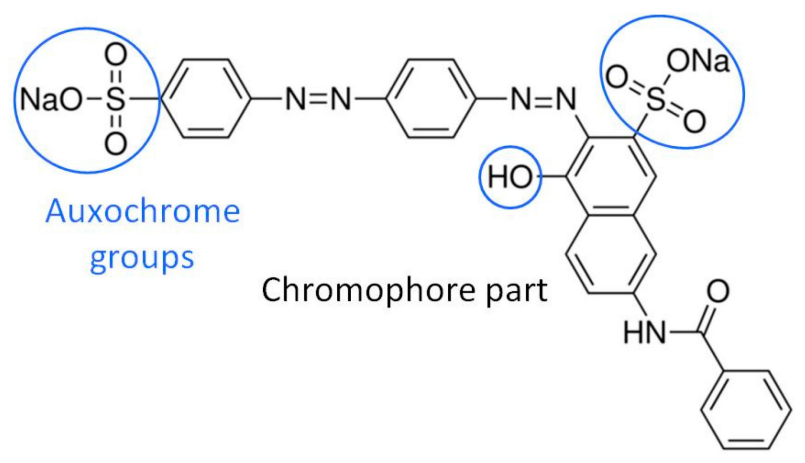

Figure 1. Molecular structure of Direct Red 81 dye.

Consequently, recovered papers contain several chromophores: lignin from mechanical pulp or highly colored Kraft pulps, and also dyes. These chromophores have to be eliminated during paper recycling in order to produce white paper. In industrial recycling lines, the bleaching treatment, following the deinking operation, usually consists of several steps using different oxidant or reducing chemicals. In this context hydrogen peroxide is used under alkaline conditions to decolorize lignin. Its anionic form, the perhydroxyl anion $\mathrm{HOO}^{-}\left(\mathrm{pKa}=11.6\right.$ at $\left.25^{\circ} \mathrm{C}\right)$, oxidizes the conjugated carbonyl groups of lignin into carboxylic acid groups, leading to higher pulp brightness. However, its effect is limited on dyes because they mainly contain unsaturated carbon-carbon bonds and unreactive azo functions. Therefore, it is often combined with a reducing agent such as sodium dithionite or formamidinesulfinic acid (FAS), although these are more expensive, in order to reach better final brightness [2]. Indeed, unlike hydrogen peroxide, these reductive chemicals are quite efficient for reduction of azo bonds and consequently dye color-stripping.

Since azo bonds are not oxidizable by $\mathrm{HOO}^{-}$, direct azo dyes are not fully degraded by conventional hydrogen peroxide bleaching stages. Therefore, in order to reduce the use of sodium dithionite and FAS in recycling lines, the idea would be to improve the decolorizing action of hydrogen peroxide by activation or catalysis.

2,2'-Bipyridine was synthesized by Fritz Blau in 1888 and discovered to form intense red ferrous salts. In 1898, he synthesized the 1,10-phenanthroline molecule (Figure 2) and showed that its properties were similar to those of 2,2'-bipyridine. He prepared iron, nickel, cobalt and copper(II) complex salts of 2,2'-bipyridine and 1,10-phenanthroline and was able to recognize them as Werner coordination compounds, with an octahedral configuration and so classed them as hexaammines [3].

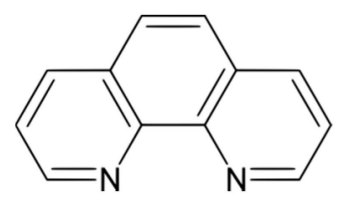

Figure 2. Molecular structure of 1,10-phenanthroline (Phen).

In $1979, \mathrm{Cu}^{+}$(phenanthroline) 2 was discovered to have a nuclease activity [4], which means that it is able to cleave the phosphodiester bonds between DNA or RNA nucleotides. The scission of DNA is supposed to occur in the presence of two co-reactants: $\mathrm{Cu}^{+}$(phenanthroline) ${ }_{2}$ and $\mathrm{H}_{2} \mathrm{O}_{2}[5,6]$. According to Sigman [5], $\mathrm{Cu}^{+}$(phenanthroline) 2 would bind to DNA (1) and the oxidation of this 
coordinate by $\mathrm{H}_{2} \mathrm{O}_{2}$ would form a cupric hydroxyl radical-like coordinate (2), responsible for the scission of DNA (3) into oligonucleotides.

$$
\mathrm{DNA}+\mathrm{Cu}^{+}(\mathrm{Phen})_{2} \stackrel{(1)}{\rightarrow} \mathrm{DNA} \cdots \mathrm{Cu}^{+}(\mathrm{Phen})_{2} \stackrel{\mathrm{H}_{2} \mathrm{O}_{2}}{\rightarrow} \mathrm{DNA} \cdots \mathrm{HOCu}^{2+}(\text { Phen })_{2}
$$

\section{$\stackrel{(3)}{\rightarrow}$ oligonucleotide products}

Copper-phenanthroline coordinates (Cu-Phen) were thus the first artificial nucleases studied in biology. They could be either bis(1,10-phenanthroline)copper as described by Sigman [4-6] or mono(1,10-phenanthroline)copper [7].

This oxidative action of $\mathrm{Cu}$-Phen complexes in the presence of $\mathrm{H}_{2} \mathrm{O}_{2}$ has been the starting point of oxidation studies of lignin compounds using copper-phenanthroline coordinates. Previous works conducted with such coordinates have reported the activation of $\mathrm{H}_{2} \mathrm{O}_{2}$ for chemical pulp delignification in alkaline conditions [8-10], leading to patents [11,12]. The results depended on the complex formulation, with an initial copper-to-phenanthroline molar ratio $\mathrm{Cu}$ :Phen of 1:1, 1:2 or 1:3. Most papers have focused on the 1:2 ratio. They have shown that the action of $\mathrm{H}_{2} \mathrm{O}_{2}$ could be enhanced thanks to $\mathrm{Cu}$-Phen complexes. Several works have also been conducted on the catalytic action of $\mathrm{Cu}$-Phen for the alkaline oxidation of lignin by either oxygen [13-17] or hydrogen peroxide [9,17], especially with lignin model compounds such as veratryl alcohol. In this context, the distribution of different copper-phenanthroline-hydroxyl complexes, depending on the $\mathrm{pH}$ and initial concentrations of copper sulfate and phenanthroline, was described by Korpi [14]. This distribution was calculated thanks to the HySS program [18], using stability constants from the NIST Standard Reference Database 46.

With a view to applying this activated or catalyzed hydrogen peroxide chemical stage to recycled fiber bleaching, some trials with deinked pulps and colored pulp were also conducted under alkaline conditions $[9,19,20]$. These showed that the dye removal index, indicating the loss of color in the CIE $L^{*} a^{*} b^{*}$ color space as defined by Sharpe and Lowe [21], was improved during a peroxide stage activated with a copper-phenanthroline complex.

This finding indicates that $\mathrm{Cu}$-Phen could make hydrogen peroxide effective in dye color-stripping although it does not decolorize dyed pulps under classical conditions.

This activation phenomenon is complex since it involves a liquid-solid system and several possible effects: (1) oxidation of the dye by $\mathrm{H}_{2} \mathrm{O}_{2}$ alone; (2) chemical action of $\mathrm{Cu}$-Phen itself on the dye molecule; (3) activation of $\mathrm{H}_{2} \mathrm{O}_{2}$ by $\mathrm{Cu}$-Phen to oxidize the dye; and (4) oxidation of the dye by free radicals originated from $\mathrm{H}_{2} \mathrm{O}_{2}$ decomposition in the presence of $\mathrm{Cu}$-Phen. All these effects were studied in detail in the work of Walger [22].

In the present paper, the focus was only on the dye/copper-phenanthroline system without any oxidant, particularly as the results were already interesting in terms of color-stripping. The Direct Red 81 dye, a commercial dye solution used in the paper industry, was selected as a model compound for hardly alkaline $\mathrm{H}_{2} \mathrm{O}_{2}$-oxidizable paper dyes present in recovered fibers. The chemical action of copper-phenanthroline complexes on Direct Red 81 in aqueous solution, in the absence of fibers, was thus examined. Since most of the previous studies only focused on alkaline $\mathrm{pH}$ with the aim of catalyzing alkaline peroxide stages, the effect of $\mathrm{pH}$ was also investigated in the present study. Copper-phenanthroline speciation using the PHREEQC software was followed as a function of $\mathrm{pH}$ and Cu:Phen ratio. The Cu-Phen/DR81 system was investigated using UV-vis spectroscopy, Cu-Phen speciation and Electron Paramagnetic Resonance (EPR) spectroscopy for the detection of copper(II) and its molecular environment.This study should contribute to the development of new wastewater treatments in the paper and textile industries as well as that of deinked pulp bleaching. 


\section{Results and Discussion}

UV-visible spectroscopy is a convenient method to characterize dyes. Dye structures and their possible modifications, due to variations of physicochemical properties of the medium or due to reactions, can be detected. The following discussion is thus supported by UV-vis analyses of the dye solution with or without $\mathrm{Cu}$-Phen. Controls without Direct Red 81 were also studied for comparison.

\subsection{UV-Visible Analysis of the Dye}

As shown in Figure 1, the DR81 molecule bears two azo groups and five aromatic nuclei, which are conjugated and constitute the chromophore part, while the auxochrome groups consist of one hydroxyl group (of the naphthol group) and two sulfonic acid groups that allow the dissolution of DR81 into water and its binding to cellulosic fibers. The dye molecule, thermally stable (no degradation at $70{ }^{\circ} \mathrm{C}$ ), was first analyzed alone at different $\mathrm{pHs}$.

Figure 3 shows the UV-vis spectra of the DR81 dye at $\mathrm{pH}$ varying from 4.5 to 12.3 , obtained with the addition of $1 \mathrm{M} \mathrm{NaOH}$ or diluted $\mathrm{H}_{2} \mathrm{SO}_{4}$.

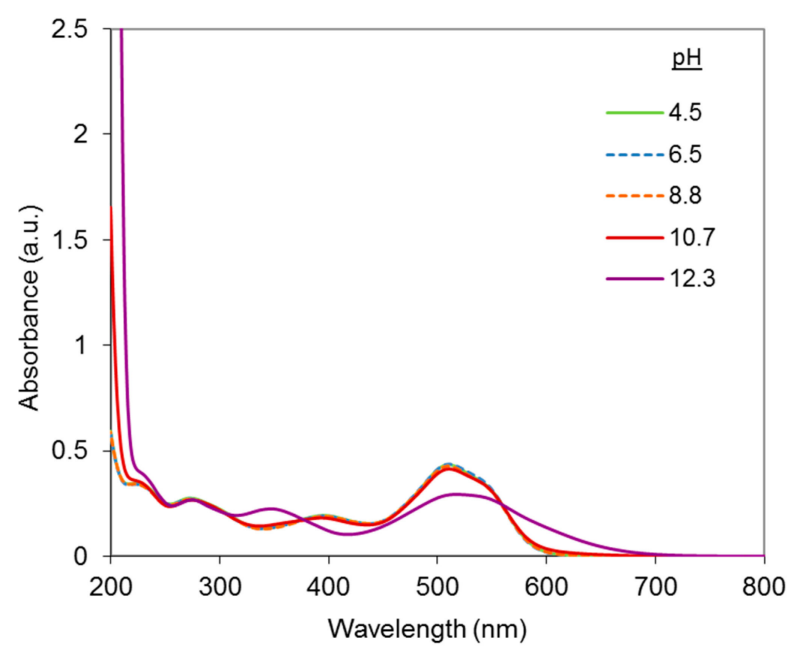

Figure 3. UV-vis spectra of the DR81 dye diluted in water $(10 \mu \mathrm{M})$, at different pHs.

In the visible range, the dye solution exhibited a maximal light absorbance at around 510-518 $\mathrm{nm}$ depending on the $\mathrm{pH}$. It was red from $\mathrm{pH} 4.5$ to $\mathrm{pH} 10.7\left(\lambda_{\max }\right.$ around $\left.510 \mathrm{~nm}\right)$ and red-purple at strong alkaline $\mathrm{pH}(12.3)\left(\lambda_{\max }=517.5 \mathrm{~nm}\right)$. This is illustrated in Figure 3 by the bathochromic and hypochromic absorbance shifts observed between $\mathrm{pH} 10.7$ and $\mathrm{pH} 12.3$.

The bathochromic shift can be attributed to the ionization of the free naphthol group of the dye. Since the acid dissociation constants of naphthol groups of common dyes are typically around or above 10 , lower $\mathrm{pHs}$ were tested in order to determine more precisely the ionization $\mathrm{pHs}$. According to Figure 3 , there is almost no change of the spectrum between $\mathrm{pH} 4.5$ and 10.7, which confirms that ionization takes place only between $\mathrm{pH} 10.7$ and 12.3 .

Therefore, in the further study on dye interactions with $\mathrm{Cu}-\mathrm{Phen}$, it was decided to focus on these two $\mathrm{pH}$ values (10.7 and 12.3) in order to study the ionized and non-ionized forms of DR81.

Before examining the dye-Cu-Phen system, the $\mathrm{Cu}$-Phen complex was first studied using (1) speciation calculations to predict the concentration- $\mathrm{pH}$ profile of $\mathrm{Cu}-\mathrm{Phen}$ species present in solution and (2) UV-vis spectroscopy to confirm the presence of coordinates and to examine how they are formed. 


\subsection{Copper-Phenanthroline Speciation}

The composition of a metal ion-ligand solution at thermodynamic equilibrium depends on the initial reagent concentrations, temperature and $\mathrm{pH}$ [23]. With the copper(II)-1,10-phenanthroline system, various species can be formed, depending on the Cu:Phen stoichiometric ratio (1:1,1:2, 1:3), typically free and hydroxylated copper, free phenanthroline (Phen) and hydroxylated or non-hydroxylated complexes such as $\mathrm{CuPhen}(\mathrm{OH})_{2}, \mathrm{Cu}$ (Phen $)_{3}{ }^{2+}, \mathrm{CuPhenOH}^{+}, \mathrm{Cu}(\text { Phen })_{2}{ }^{2+}$, etc. [24-27].

Modeling using the PHREEQC software allowed the calculation of equilibrium concentration-pH profiles for each $\mathrm{Cu}$-Phen species including free copper and free phenanthroline, with or without considering the occurrence of coordinate precipitation. The predicted results are shown in Figure 4. They were calculated for $\mathrm{Cu}$ :Phen $=1: 1,1: 2$ and 1:3 with an initial $\mathrm{CuSO}_{4}$ concentration of $15 \mu \mathrm{M}$ at $25^{\circ} \mathrm{C}$, from $\mathrm{pH} 6.5$ to $\mathrm{pH}$ 12.5. In the case "with solid phase", precipitation is made possible when the solubility product for one complex is attained. In the alternative case, entitled "without solid phases", all species remain soluble and a certain degree of over-saturation is thus admitted for some of them (which allows considering cases where precipitation occurs very slowly at a certain degree of over-saturation). In the "with solid phase" case, total solids are represented by one profile gathering every copper-based precipitate theoretically present.
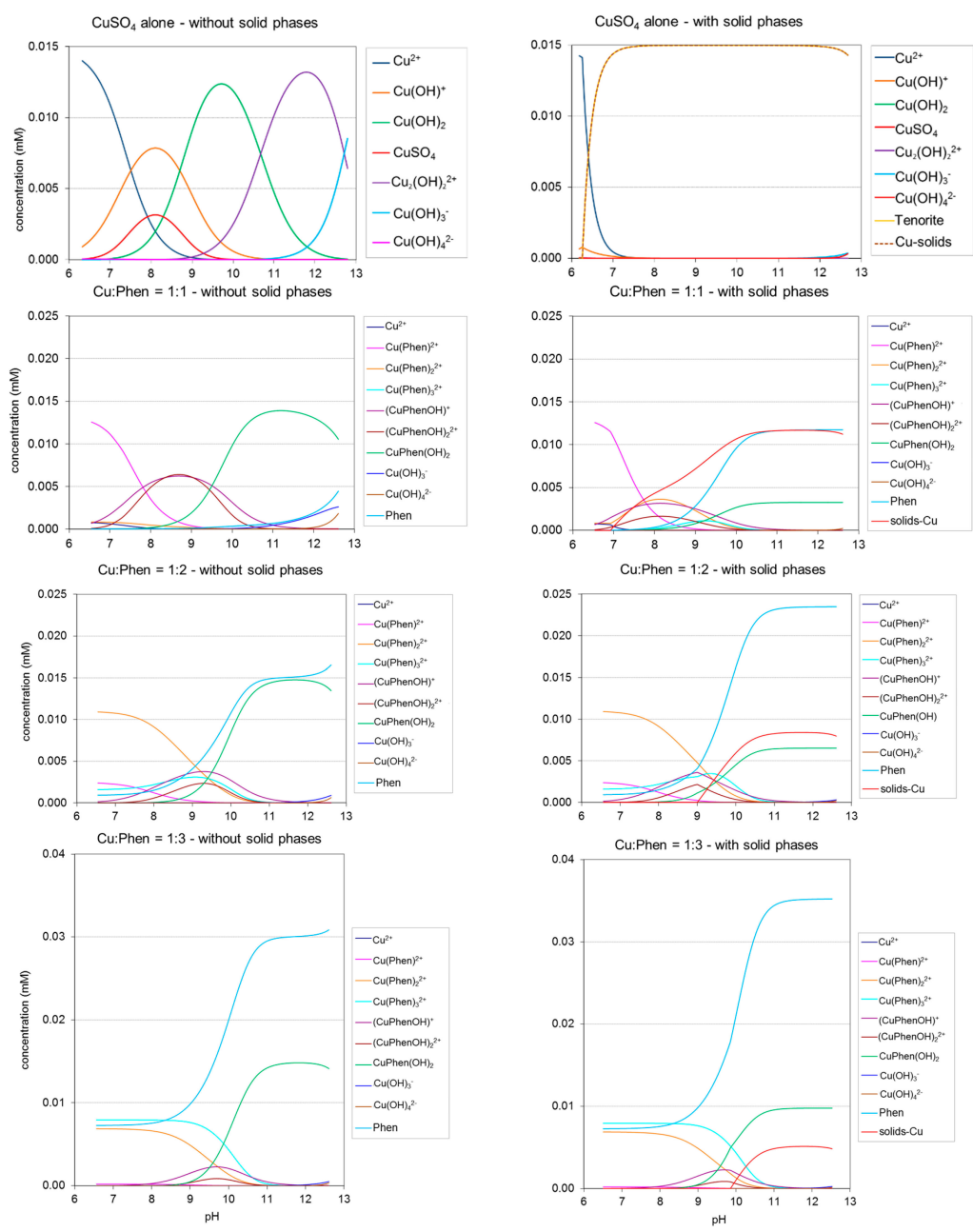

Figure 4. Calculated distributions of different species in $\mathrm{CuSO}_{4}$ and $\mathrm{Cu}$-Phen solutions as a function of $\mathrm{pH}$. $\mathrm{CuSO}_{4}$ alone, $\mathrm{Cu}$ :Phen =1:1, 1:2 and 1:3; initial $\mathrm{CuSO}_{4}$ concentration $[\mathrm{Cu}]=15 \mu \mathrm{M}$ at $25^{\circ} \mathrm{C}$, with or without the occurrence of precipitation. 
Without solid phase, under the calculation conditions, copper sulfate gave rise to a majority of free cupric ions from $\mathrm{pH} 6$ to 7.5. Increasing the $\mathrm{pH}$ raised the degree of hydroxylation of copper, reaching a majority of $\mathrm{Cu}(\mathrm{OH})_{3}{ }^{-}$above $\mathrm{pH}$ 12.7. With the occurrence of precipitation, cupric ions appeared to be replaced by tenorite $(\mathrm{CuO})$ from $\mathrm{pH} 6$ to 7.4. Above 7.4, tenorite should be the only copper species present until $\mathrm{pH} 12$.

In the case of $\mathrm{Cu}$ :Phen $=1: 1$, the calculated distributions were much different with or without solid phase. In the case "with solid phase", most of the copper precipitates, starting at $\mathrm{pH} 7$ and reaching a maximum $(0.012 \mathrm{mM})$ above $\mathrm{pH} 10$, leading to a high amount of free phenanthroline in solution. The experimental observation of the prepared mixtures confirmed this statement, since the Cu-Phen (1:1) stock solution was actually not stable and precipitates were visible after some days or weeks at rest.

Concerning the other $\mathrm{Cu}$ :Phen molar ratios (1:2 and 1:3), the modeling "with solid phase" resulted in lower amounts of precipitates (around $0.008 \mathrm{mM}$ above $\mathrm{pH} 10.5$ and $0.005 \mathrm{mM}$ above $\mathrm{pH} 11$, respectively, compared to $0.012 \mathrm{mM}$ at a molar ratio of 1:1). Indeed, experimentally, these solutions were found more stable since no precipitate was visible after several weeks. Therefore, it appears that higher Phen:Cu molar ratios favor the existence of soluble complexes between copper and phenanthroline, rather than precipitated complexes, and that the calculated results are in general accordance with visual observations.

The distributions presented in Figure 4 differ from those described in the literature by Korpi et al. [14] since the initial concentrations (chosen to fit our experimental range) were much lower: $[\mathrm{Cu}]=15 \mu \mathrm{M}$ vs. $10 \mathrm{mM}$. The conditions of Korpi et al. were also tested for comparison and a good fit was found when the calculations did not allow precipitation. This shows the advantage of using the PHREEQC software, which takes into account the occurrence of solid precipitates and their physiochemical equilibria with dissolved species in the medium.

For further use in the investigation of $\mathrm{Cu}$-Phen interaction with the dye at different $\mathrm{pHs}$, three $\mathrm{pH}$ values were focused on: 6.5 (unionized dye at near-neutral $\mathrm{pH}$ ), 10.7 (unionized dye at alkaline $\mathrm{pH}$ ), and 12.3 (ionized dye at strongly alkaline $\mathrm{pH}$ ). The abundances of the species at these specific $\mathrm{pHs}$ are gathered in Table 1 (without precipitation) and Table 2 (with precipitation) as a function of the initial $\mathrm{Cu}:$ Phen molar ratio.

According to Figure 4 and Tables 1 and 2, two main features arise: (1) CuPhen $(\mathrm{OH})_{2}$ appears to be the major copper species at alkaline $\mathrm{pH}$ ( 81 to $98 \%$ of total $\mathrm{Cu}$ in the case "without precipitation") and (2), free phenanthroline is still present in the medium. As expected, free phenanthroline concentration (last row in Table 1) increases significantly when the Cu:Phen ratio varies from 1:1 to 1:3. Besides, more hydroxylated species are logically found at $\mathrm{pH} 12.3$ vs. 10.7. Whatever the $\mathrm{pH}, \mathrm{Cu}(\mathrm{Phen})^{2+}$ is almost inexistent, and the other non-hydroxylated species $\mathrm{Cu}(\mathrm{Phen}){ }_{2}{ }^{2+}$ and $\mathrm{Cu}(\mathrm{Phen}){ }_{3}{ }^{2+}$ are only present at $\mathrm{pH}$ 10.7 , at low concentrations.

Table 1. Predicted abundances (expressed as percentages of total $\mathrm{Cu}$ ) of the different species at $\mathrm{pH} 6.5$, 10.7 and 12.3, for Cu:Phen molar ratios = 1:0, 1:1, 1:2 and 1:3, with an initial $\mathrm{CuSO}_{4}$ concentration of $15 \mu \mathrm{M}$ at $25^{\circ} \mathrm{C}$, assuming no precipitation occurrence. The results are given as molar percentages of total [Cu].

\begin{tabular}{|c|c|c|c|c|c|c|c|c|c|c|c|c|}
\hline Cu:Phen & & 1:0 & & & 1:1 & & & $1: 2$ & & & $1: 3$ & \\
\hline $\mathrm{pH}$ & 6.5 & 10.7 & 12.3 & 6.5 & 10.7 & 12.3 & 6.5 & 10.7 & 12.3 & 6.5 & 10.7 & 12.3 \\
\hline $\mathrm{Cu}^{2+}$ & 90.2 & $\varepsilon$ & $\varepsilon$ & 5.1 & $\varepsilon$ & $\varepsilon$ & $\varepsilon$ & $\varepsilon$ & $\varepsilon$ & $\varepsilon$ & $\varepsilon$ & $\varepsilon$ \\
\hline $\mathrm{CuOH}^{+}$ & 8.8 & 0.5 & $\varepsilon$ & 0.5 & $\varepsilon$ & $\varepsilon$ & $\varepsilon$ & $\varepsilon$ & $\varepsilon$ & $\varepsilon$ & $\varepsilon$ & $\varepsilon$ \\
\hline $\mathrm{Cu}(\mathrm{OH})_{2}$ & 0.1 & 48.1 & 1.6 & $\varepsilon$ & 1.7 & 0.3 & $\varepsilon$ & 0.1 & 0.1 & $\varepsilon$ & $\varepsilon$ & $\varepsilon$ \\
\hline $\mathrm{CuSO}_{4}$ & 0.3 & $\varepsilon$ & $\varepsilon$ & $\varepsilon$ & $\varepsilon$ & $\varepsilon$ & $\varepsilon$ & $\varepsilon$ & $\varepsilon$ & $\varepsilon$ & $\varepsilon$ & $\varepsilon$ \\
\hline $\mathrm{Cu}_{2}(\mathrm{OH})_{2}{ }^{2+}$ & 0.6 & $\varepsilon$ & $\varepsilon$ & $\varepsilon$ & $\varepsilon$ & $\varepsilon$ & $\varepsilon$ & $\varepsilon$ & $\varepsilon$ & $\varepsilon$ & $\varepsilon$ & $\varepsilon$ \\
\hline $\mathrm{Cu}(\mathrm{OH})_{3}^{-}$ & $\varepsilon^{a}$ & 51.2 & 77.4 & $\varepsilon$ & 1.8 & 14.5 & $\varepsilon$ & 0.1 & 3.1 & $\varepsilon$ & $\varepsilon$ & 1.6 \\
\hline $\mathrm{Cu}(\mathrm{OH})_{4}{ }^{2-}$ & $\varepsilon$ & 0.2 & 21.0 & $\varepsilon$ & $\varepsilon$ & 3.9 & $\varepsilon$ & $\varepsilon$ & 0.8 & $\varepsilon$ & $\varepsilon$ & 0.4 \\
\hline $\mathrm{Cu}(\mathrm{Phen})^{2+}$ & / & $/$ & / & 84.3 & $\varepsilon$ & $\varepsilon$ & 15.9 & $\varepsilon$ & $\varepsilon$ & 1.3 & $\varepsilon$ & $\varepsilon$ \\
\hline $\mathrm{Cu}(\text { Phen })_{2}{ }^{2+}$ & I & l & / & 5.5 & $\varepsilon$ & $\varepsilon$ & 72.8 & 0.6 & $\varepsilon$ & 45.8 & 1.1 & $\varepsilon$ \\
\hline $\mathrm{Cu}(\mathrm{Phen})_{3}^{2+}$ & / & / & / & $\varepsilon$ & $\varepsilon$ & $\varepsilon$ & 10.6 & 1.4 & $\varepsilon$ & 52.8 & 4.9 & $\varepsilon$ \\
\hline$(\mathrm{CuPhenOH})^{+}$ & / & / & / & 4.1 & 5.8 & 0.2 & 0.8 & 5.9 & 0.2 & 0.1 & 5.7 & 0.2 \\
\hline$(\mathrm{CuPhenOH})_{2}{ }^{2+}$ & 1 & i & / & 0.4 & 0.9 & $\varepsilon$ & $\varepsilon$ & 0.9 & $\varepsilon$ & $\varepsilon$ & 0.8 & $\varepsilon$ \\
\hline CuPhen $(\mathrm{OH})_{2}$ & l & / & / & $\varepsilon$ & 89.7 & 81.2 & $\varepsilon$ & 91.1 & 95.9 & $\varepsilon$ & 87.4 & 97.7 \\
\hline Phen & / & i & / & 0.1 & 3.5 & 18.7 & 6.1 & 96.8 & 104.0 & 48 & 189 & 202 \\
\hline
\end{tabular}


Table 2. Predicted abundances (expressed as percentages of total $\mathrm{Cu}$ ) of the different species at $\mathrm{pH}$ 6.5, 10.7 and 12.3, for $\mathrm{Cu}$ :Phen molar ratios = 1:0, 1:1, 1:2 and 1:3, with an initial $\mathrm{CuSO}_{4}$ concentration of $15 \mu \mathrm{M}$ at $25^{\circ} \mathrm{C}$, assuming the occurrence of solids precipitation. The results are given as molar percentages of total [Cu].

\begin{tabular}{|c|c|c|c|c|c|c|c|c|c|c|c|c|}
\hline Cu:Phen & & 1:0 & & & 1:1 & & & $1: 2$ & & & $1: 3$ & \\
\hline $\mathrm{pH}$ & 6.5 & 10.7 & 12.3 & 6.5 & 10.7 & 12.3 & 6.5 & 10.7 & 12.3 & 6.5 & 10.7 & 12.3 \\
\hline $\mathrm{Cu}^{2+}$ & 29.9 & $\varepsilon$ & $\varepsilon$ & 5.1 & $\varepsilon$ & $\varepsilon$ & $\varepsilon$ & $\varepsilon$ & $\varepsilon$ & $\varepsilon$ & $\varepsilon$ & $\varepsilon$ \\
\hline $\mathrm{CuOH}^{+}$ & 3.0 & $\varepsilon$ & $\varepsilon$ & 0.5 & $\varepsilon$ & $\varepsilon$ & $\varepsilon$ & $\varepsilon$ & $\varepsilon$ & $\varepsilon$ & $\varepsilon$ & $\varepsilon$ \\
\hline $\mathrm{Cu}(\mathrm{OH})_{2}$ & $\varepsilon^{\mathrm{a}}$ & $\varepsilon$ & $\varepsilon$ & $\mathcal{\varepsilon}$ & $\varepsilon$ & $\varepsilon$ & $\varepsilon$ & $\varepsilon$ & $\varepsilon$ & $\varepsilon$ & $\varepsilon$ & $\varepsilon$ \\
\hline $\mathrm{CuSO}_{4}$ & 0.1 & $\varepsilon$ & $\varepsilon$ & $\varepsilon$ & $\varepsilon$ & $\varepsilon$ & $\varepsilon$ & $\varepsilon$ & $\varepsilon$ & $\varepsilon$ & $\varepsilon$ & $\varepsilon$ \\
\hline $\mathrm{Cu}_{2}(\mathrm{OH})_{2}{ }^{2+}$ & 0.1 & $\varepsilon$ & $\varepsilon$ & $\varepsilon$ & $\varepsilon$ & $\varepsilon$ & $\varepsilon$ & $\varepsilon$ & $\varepsilon$ & $\varepsilon$ & $\varepsilon$ & $\varepsilon$ \\
\hline $\mathrm{Cu}(\mathrm{OH})_{3}{ }^{-}$ & $\mathcal{\varepsilon}$ & $\varepsilon$ & 0.9 & $\varepsilon$ & $\varepsilon$ & 0.9 & $\varepsilon$ & $\varepsilon$ & 0.9 & $\varepsilon$ & $\varepsilon$ & 0.9 \\
\hline $\mathrm{Cu}(\mathrm{OH})_{4}^{2-}$ & $\varepsilon$ & $\varepsilon$ & 0.3 & $\varepsilon$ & $\varepsilon$ & 0.3 & $\varepsilon$ & $\varepsilon$ & 0.3 & $\varepsilon$ & $\varepsilon$ & 0.3 \\
\hline $\mathrm{Cu}(\text { Phen })^{2+}$ & / & / & / & 84.3 & $\varepsilon$ & $\varepsilon$ & 15.9 & $\varepsilon$ & $\varepsilon$ & 1.3 & $\varepsilon$ & $\varepsilon$ \\
\hline $\mathrm{Cu}(\text { Phen })_{2}{ }^{2+}$ & / & / & / & 5.5 & 0.1 & $\varepsilon$ & 72.8 & 0.4 & $\varepsilon$ & 45.8 & 0.9 & $\varepsilon$ \\
\hline $\mathrm{Cu}(\text { Phen })_{3}^{2+}$ & / & / & / & $\varepsilon$ & 0.2 & $\varepsilon$ & 10.6 & 1.5 & $\varepsilon$ & 52.8 & 4.6 & $\varepsilon$ \\
\hline$(\mathrm{CuPhenOH})^{+}$ & / & / & / & 4.1 & 1.4 & $\varepsilon$ & 0.8 & 2.7 & 0.1 & 0.1 & 4.0 & 0.1 \\
\hline$(\mathrm{CuPhenOH})_{2}{ }^{2+}$ & / & / & / & 0.4 & $\varepsilon$ & $\varepsilon$ & $\varepsilon$ & 0.2 & $\varepsilon$ & $\varepsilon$ & 0.4 & $\varepsilon$ \\
\hline $\mathrm{CuPhen}(\mathrm{OH})_{2}$ & / & / & / & $\varepsilon$ & 21.3 & 21.7 & $\varepsilon$ & 41.7 & 43.5 & $\varepsilon$ & 60.9 & 65.2 \\
\hline Phen & / & / & / & $\varepsilon$ & 76.5 & 78.2 & 6.1 & 150.1 & 156.5 & 48.5 & 219.1 & 234.7 \\
\hline Tenorite & 66.9 & 100.0 & 98.8 & $\varepsilon$ & 77.0 & 77.0 & $\varepsilon$ & 53.4 & 55.3 & $\varepsilon$ & 29.2 & 33.5 \\
\hline Solids-Cu & 66.9 & 100.0 & 98.8 & $\varepsilon$ & 77.0 & 77.0 & $\varepsilon$ & 53.4 & 55.3 & $\varepsilon$ & 29.2 & 33.5 \\
\hline
\end{tabular}

At near neutral $\mathrm{pH}$ (6.5), copper and phenanthroline mainly form $\mathrm{Cu}(\mathrm{Phen})^{2+}, \mathrm{Cu}(\mathrm{Phen})_{2}{ }^{2+}$ and $\mathrm{Cu}(\mathrm{Phen})_{3}{ }^{2+}$, at relative percentages depending on the $\mathrm{Cu}$ :Phen molar ratio.As explained before, when the $\mathrm{Cu}$-Phen stock solution with a molar ratio of 1:1 was stored for several days, the solution eventually precipitated. Therefore, all the experiments that will be described in the next paragraphs were performed with freshly prepared solutions whatever the $\mathrm{Cu}$ :Phen molar ratio, and no precipitation was observed at initial time. Consequently, all explanations will be referred to predictions "without solids".

\subsection{Analysis of the Cu-Phen Complex by UV-Vis Spectroscopy}

The $\mathrm{Cu}$-Phen complexation was mainly analyzed by UV-visible spectroscopy. The study was conducted at alkaline $\mathrm{pH}$ (12.3), i.e., the $\mathrm{pH}$ at which the complex is supposed to be used for $\mathrm{H}_{2} \mathrm{O}_{2}$ color-stripping activation. Some analyses were also carried out at $\mathrm{pH} 10.7$ ( $\mathrm{pH}$ of dye ionization) for comparison. The contribution of $\mathrm{CuSO}_{4}$ and Phen alone to the UV-vis absorbance was first analyzed.

\subsection{1. $\mathrm{CuSO}_{4}$}

Copper sulfate absorbance spectra at $\mathrm{pH} 10.7$ and 12.3 are shown in Figure 5.

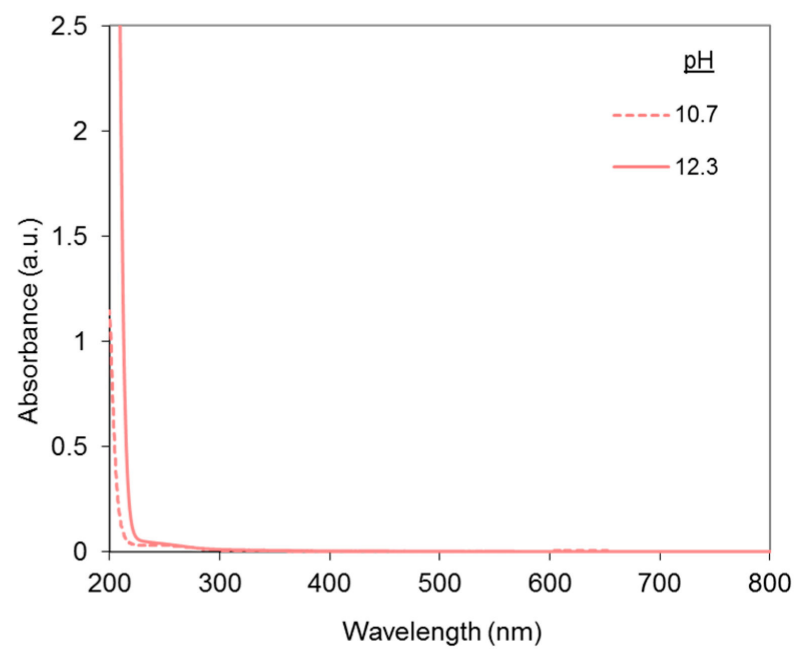

Figure 5. Absorbance spectra of copper sulfate solutions at $\mathrm{pH} 10.7$ and 12.3 , with $\left[\mathrm{CuSO}_{4}\right]=15 \mu \mathrm{M}$. 
At the low concentration used in this study, a slight absorption contribution can be noticed in the UV range and no absorbance is detected in the visible range. Yet, the blue shade of copper(II) is visible at higher concentrations.

\subsubsection{Phenanthroline}

The UV-vis absorbance spectra of phenanthroline alone at pH 10.7 and 12.3 are presented in Figure 6.

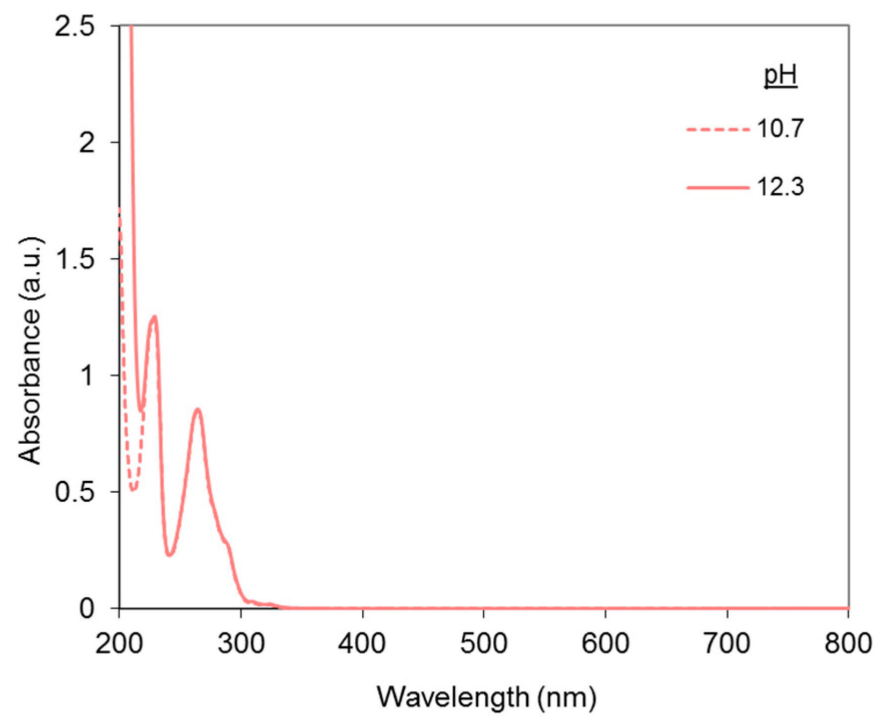

Figure 6. Absorbance spectra of 1,10-phenanthroline at $\mathrm{pH} 10.7$ and 12.3, with [Phen] $=30 \mu \mathrm{M}$ (equivalent to the amount of phenanthroline with the following molar ratio: DR81:Cu $=1: 1.5$, $\mathrm{Cu}:$ Phen $=1: 2$, and $[\mathrm{Cu}]=15 \mu \mathrm{M})$.

Two peaks are observed at 228.5-229 $\mathrm{nm}$ and $264 \mathrm{~nm}$ and nothing appears in the visible range. This is in accordance with previous results from Yamazaki et al. [28], who reported the first peak around $227 \mathrm{~nm}$ and the second peak at $263 \mathrm{~nm}$, at near-neutral $\mathrm{pH}$ in solutions containing hexane. Therefore, phenanthroline's absorbance will not interfere with the dye's signal in the visible range. The same authors reported molar extinction coefficients at various wavelengths: $\log \varepsilon_{\max }(227 \mathrm{~nm})=5.3 ; \log \varepsilon_{\max }(263 \mathrm{~nm})=5.2$. In the present work, slightly different values were found: $\log \varepsilon_{\max }(228.5 \mathrm{~nm})=4.6$, and $\log \varepsilon_{\max }(264 \mathrm{~nm})=4.5$, probably attributable to differences of analytical conditions (different solvents and $\mathrm{pHs}$ ). However, the result for the second peak is very close to that of Armaroli et al. [29] in a $\mathrm{CH}_{2} \mathrm{Cl}_{2}$ solution $\left(\log \varepsilon_{\max }(264 \mathrm{~nm})=4.5\right)$, and to that of Vallée et al. [30] with crystalline dihydrochloride phenanthroline $\left(\log \varepsilon_{\max }(265 \mathrm{~nm})=4.5\right)$. It can also be noticed that the phenanthroline spectra presented in Figure 6 were identical at both pHs except from 200 to $220 \mathrm{~nm}$, where the absorbance of sodium hydroxide interfered.

\subsubsection{Cu-Phen}

The absorbance spectra of $\mathrm{Cu}$-Phen solutions at $\mathrm{pH} 10.7$ and $\mathrm{pH} 12.3$ are presented in Figure 7 with $\mathrm{Cu}$ :Phen molar ratios varying from 1:1 to 1:3.The $\mathrm{Cu}$-Phen spectra are very close to those of Phen alone (Figure 6). This was expected since Ni et al. reported two peaks at $227 \mathrm{~nm}$ and $264.5 \mathrm{~nm}$ for $\mathrm{Cu}$ (Phen $)_{2}{ }^{2+}$ prepared with $\mathrm{Cu}\left(\mathrm{NO}_{3}\right)_{2}$ and 1,10-phenanthroline monohydrate in a tris- $\mathrm{HCl}$ buffer ( $\mathrm{pH}$ 7.4) [31]. Figure 7 indicates that at each $\mathrm{pH}$, the absorbance of copper-phenanthroline increases almost proportionally to the initial concentration of phenanthroline in the complex, in accordance with Beer-Lambert's law. As observed with Phen alone, at the concentrations used in the present study, Cu-Phen solutions did not exhibit any signal in the visible range. However, at various pHs and Cu:Phen molar ratios, slight differences between Phen and Cu-Phen can be observed in 
terms of maximum absorption wavelengths, showing the effect of coordination between copper and phenanthroline. Moreover, no clear difference was observed between $\mathrm{pH} 10.7$ and 12.3, suggesting that coordination was not influenced by $\mathrm{pH}$, probably because at these $\mathrm{pHs}$, the major copper species is $\mathrm{CuPhen}(\mathrm{OH})_{2}$. In depth examination of $\mathrm{Cu}$-Phen coordination by EPR spectroscopy will be presented in the following section.

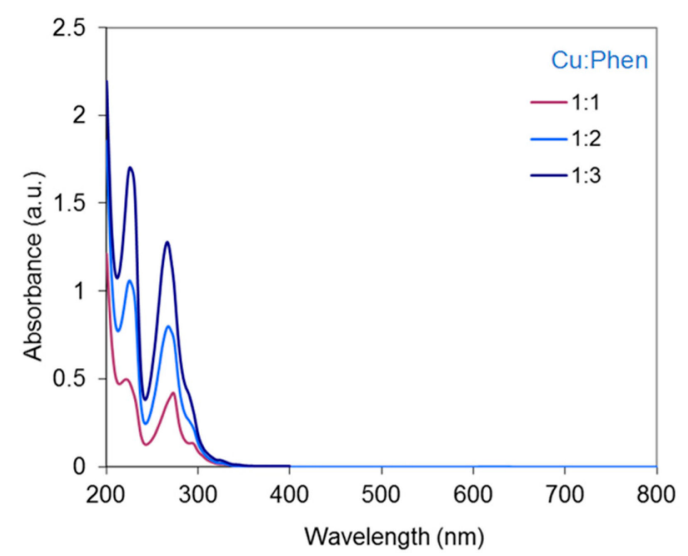

(a)

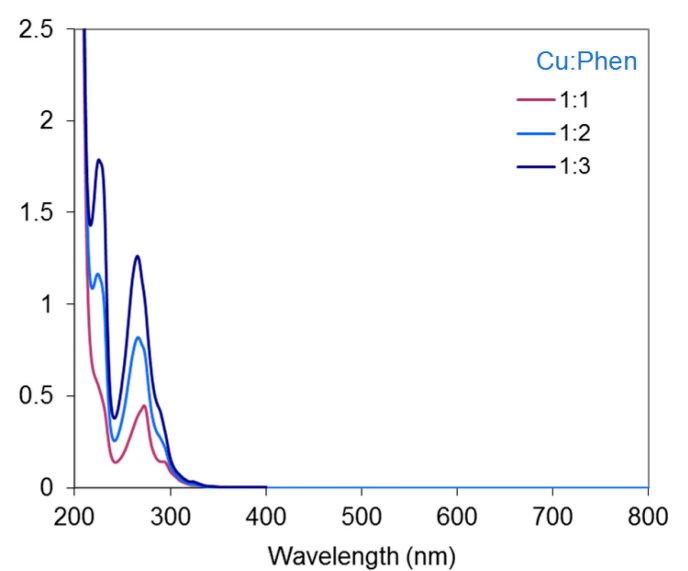

(b)

Figure 7. Absorbance spectra of the $\mathrm{Cu}-\mathrm{Phen}$ solutions at (a) $\mathrm{pH} 10.7$ and (b) $\mathrm{pH} 12.3$, with Cu:Phen molar ratio $=1: 1,1: 2$ and $1: 3$, and $[\mathrm{Cu}]=15 \mu \mathrm{M}$.

\subsubsection{Evidence of $\mathrm{Cu}$-Phen Coordination by EPR}

Paramagnetic species such as copper(II) are detectable by EPR spectroscopy, especially at very low temperatures, at which hyperfine structures can be observed. An example of this is shown in Figure 8. The technique and experimental conditions are presented in Section 4.5.

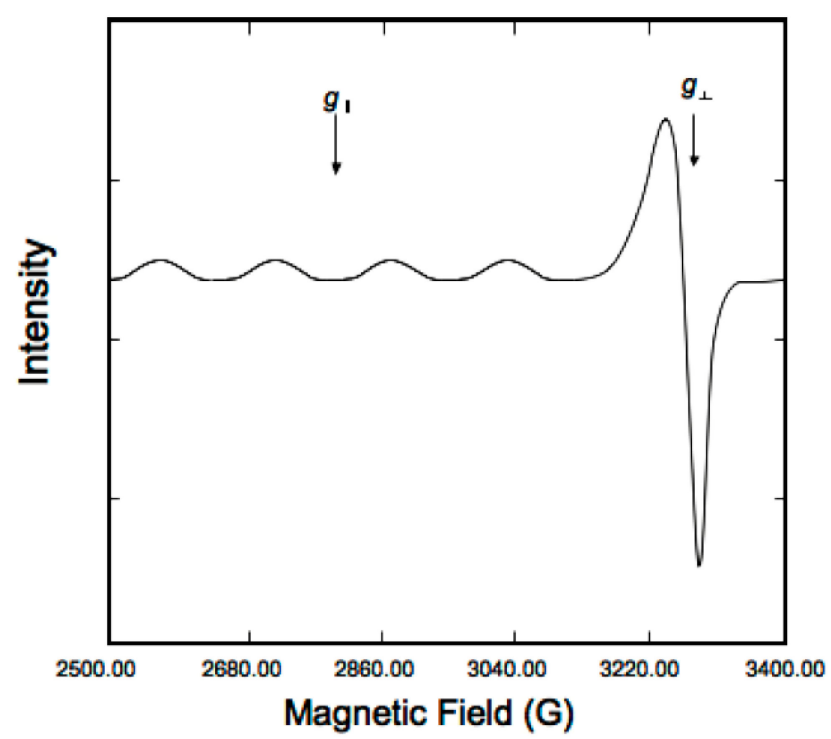

Figure 8. Typical X-band EPR spectrum of copper(II) compounds [32].

X-band EPR spectra of the $\mathrm{Cu}$ salt $\left(\mathrm{CuSO}_{4}\right)$ and of $\mathrm{Cu}$-Phen were recorded at $100 \mathrm{~K}$ and at $\mathrm{pH}$ 12.3 (Figure 9). EPR detection of copper(II) requiring millimolar concentration, these analyses were performed with $[\mathrm{Cu}]=1.5 \mathrm{mM}$ (100 times higher than for the UV experiments). 
Both EPR spectra are characteristic of $S=\frac{1}{2}$ systems and consistent with the presence of mononuclear paramagnetic $\mathrm{Cu}(\mathrm{II})$ ( $\mathrm{a} \mathrm{d}^{9}$ ion), since $\mathrm{Cu}(\mathrm{I})\left(\mathrm{a} \mathrm{d}^{10} \mathrm{ion}\right)$ is diamagnetic. It is therefore evidenced that $\mathrm{Cu}$ is present in solution in its oxidized state, $\mathrm{Cu}^{2+}$, and that the presence of phenanthroline does not affect its degree of oxidation. However, when phenanthroline is present in solution, the EPR spectrum is significantly modified, which shows a strong modification of the copper environment due to the coordination between $\mathrm{Cu}^{2+}$ and phenanthroline. The effect of adding the dye is presented in the next paragraph.

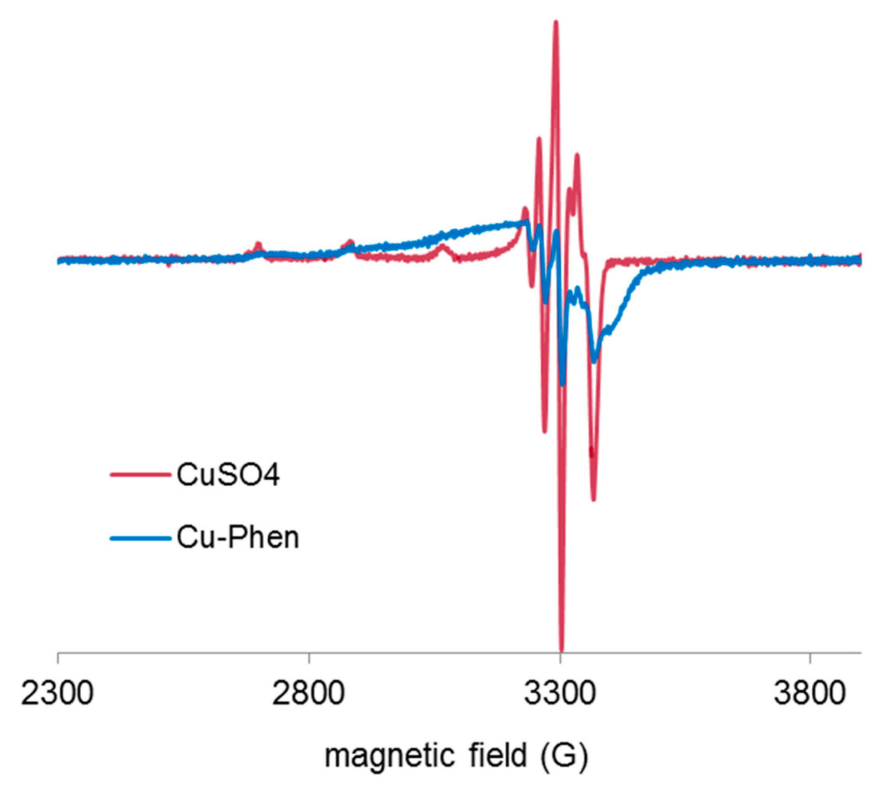

Figure 9. Experimental X-band EPR spectra recorded at $100 \mathrm{~K}$ in frozen aqueous solutions of $\mathrm{CuSO}_{4}$ and $\mathrm{Cu}$-Phen at $\mathrm{pH} 12.3$, with $\mathrm{Cu}$ :Phen molar ratio $=1: 2$ and $[\mathrm{Cu}]=1.5 \mathrm{mM}$.

\subsection{Analysis of the DR81 Dye/Cu-Phen System}

The possibility of dye complexation with $\mathrm{CuSO}_{4}$ and $\mathrm{Cu}$-Phen was first examined by UV-vis spectroscopy. The study was mainly conducted at strong alkaline $\mathrm{pH}$ since the $\mathrm{Cu}-\mathrm{Phen}$ complex is supposed to be used as an activator of alkaline $\mathrm{H}_{2} \mathrm{O}_{2}$ color-stripping treatments for dyed cellulosic fibers. Some investigations were also performed at lower $\mathrm{pH}$ for a better understanding of the phenomena. Before studying the complete three-component system, several controls were performed with dye-copper alone and dye-phenanthroline alone.

\subsubsection{Dye $/ \mathrm{CuSO}_{4}$ System}

As a first control, $\mathrm{CuSO}_{4}$ was introduced at alkaline $\mathrm{pH}$ in the dye solution at a dye:Cu molar ratio of 1:1.5. Results are presented in Figure 10. The dye is responsible for the total absorbance in the visible range. Adding $\mathrm{CuSO}_{4}$ to the dye solution modifies the absorbance, especially at $\mathrm{pH} 10.7$, with a strong hypochromic effect ( $33 \%$ absorbance decrease at $510 \mathrm{~nm})$, which evidences a significant modification of the dye chromophore structure due to coordination. 


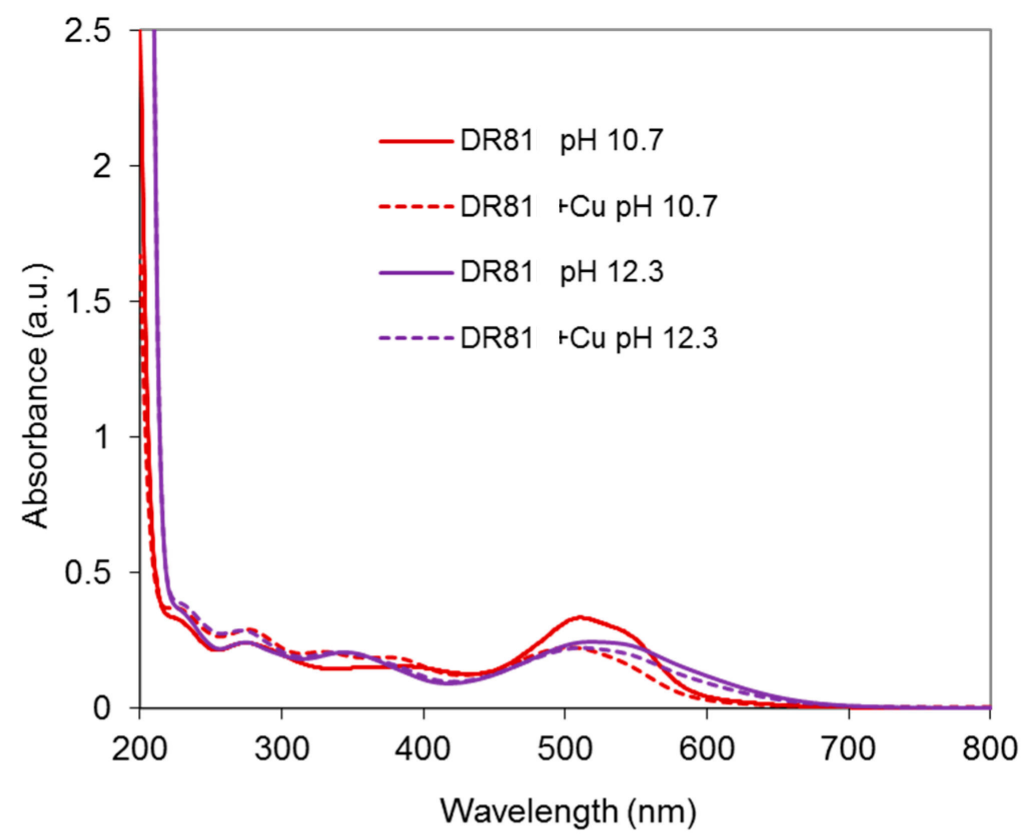

Figure 10. Absorbance spectra of the dye/copper sulfate system at $\mathrm{pH} 10.7$ and 12.3, with $\mathrm{DR} 81: \mathrm{CuSO}_{4}$ molar ratio $=1: 1.5$ and $[\mathrm{DR} 81]=10 \mu \mathrm{M}$, compared to the dye alone at the same $\mathrm{pHs}$.

\subsubsection{Dye/Phenanthroline System}

As a second control, phenanthroline alone was added to the dye solution. The resulting spectra are presented in Figure 11. It is shown that the chromophore structure of the dye remains unchanged with or without phenanthroline. Hence, no interaction between phenanthroline and the dye is evidenced.

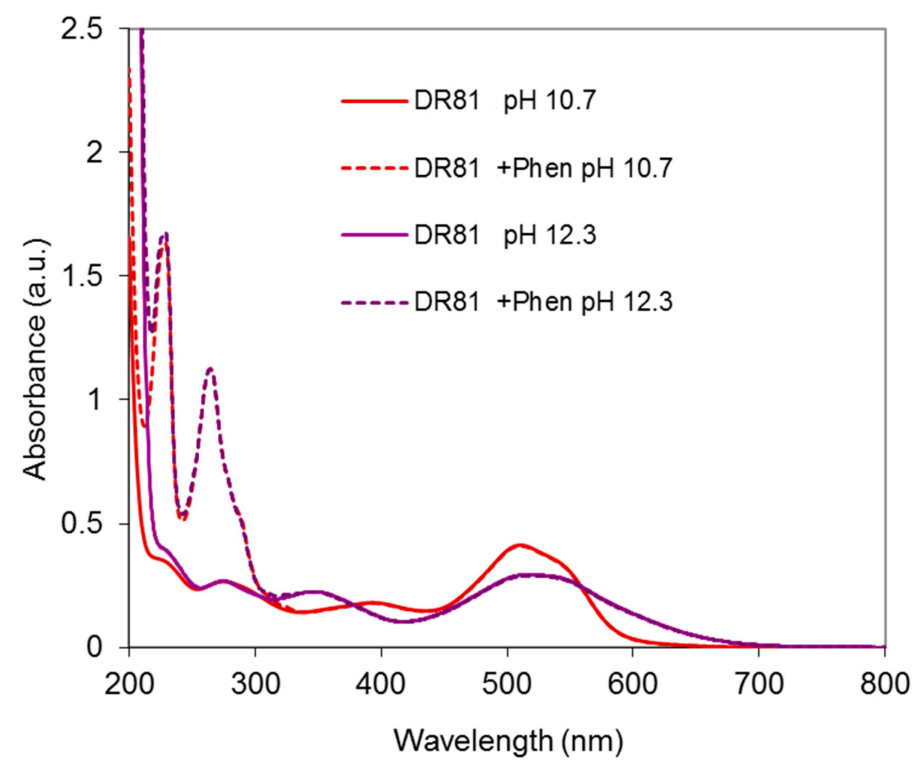

Figure 11. Absorbance spectra of the dye/phenanthroline system at $\mathrm{pH} 10.7$ and 12.3, with DR81:Phen molar ratio $=1: 3$ and [DR81] $=10 \mu \mathrm{M}$ (equivalent to the amount of phenanthroline with DR81:Cu molar ratio $=1: 1.5, \mathrm{Cu}$ :Phen molar ratio $=1: 2$, and $[\mathrm{Cu}]=15 \mu \mathrm{M}$ ), compared to the dye alone at the same pHs. 


\subsubsection{Dye/Cu-Phen System}

Results at Alkaline $\mathrm{pH}$

The system was studied at $\mathrm{pH} 10.7$ and 12.3 and at three $\mathrm{Cu}$ :Phen ratios, to see the effect of dye ionization and copper-phenanthroline species abundance, as presented earlier. Figure 12 displays the absorbance spectra obtained at $\mathrm{pH}$ 10.7. At this $\mathrm{pH}$, the dye is not ionized. The spectrum of the dye/Cu-Phen solution appears quite different from that of the dye alone, especially in the visible range, with a strong hypochromic effect similar to that observed with $\mathrm{CuSO}_{4}$ alone (Figure 10). The absorbance decay reached $33 \%$ for $\mathrm{Cu}$ :Phen molar ratios of $1: 2$ and $1: 3$ and for pure $\mathrm{CuSO}_{4}$, whereas it reached $45 \%$ at $510 \mathrm{~nm}$ for Cu:Phen at 1:1 molar ratio, thus showing that almost $50 \%$ of "color stripping" effect can be obtained by simple addition of $\mathrm{Cu}-\mathrm{Phen}$ in the dye solution.

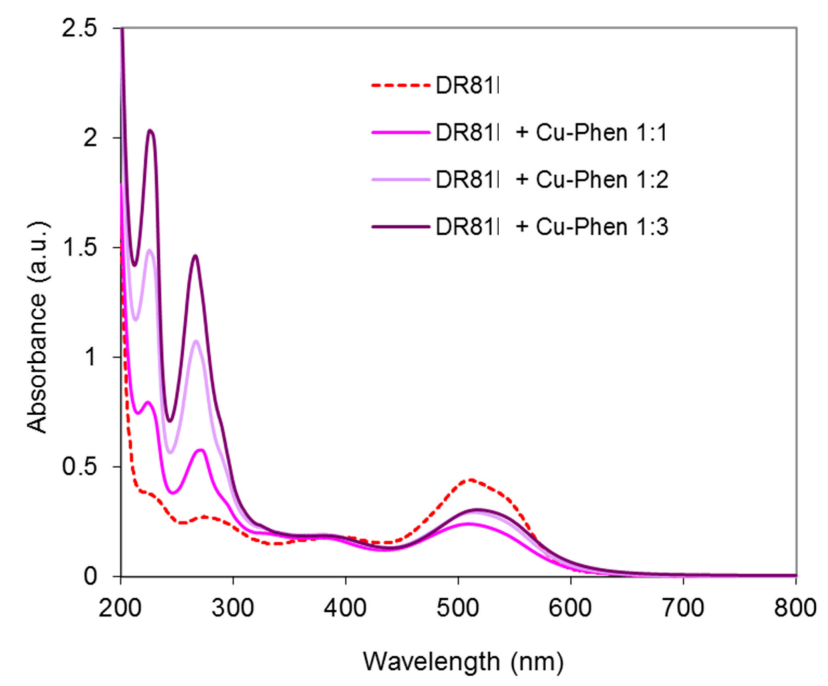

Figure 12. Absorbance spectra of the dye/copper-phenanthroline system at $\mathrm{pH}$ 10.7, with Cu:Phen molar ratio $=1: 1,1: 2$ and 1:3, DR81:Cu molar ratio= 1:1.5, and [DR81] $=10 \mu \mathrm{M}$, compared to the dye alone at the same $\mathrm{pH}$.

In addition to the hypochromic effect, a bathochromic shift is observed in some cases: the maximum absorption wavelength of the dye at $510 \mathrm{~nm}$ was shifted to $513.5 \mathrm{~nm}$ in the presence of Cu:Phen at a molar ratio of 1:2, and to $517 \mathrm{~nm}$ at a molar ratio of 1:3. This evidences the coordination between dye and copper, even in the presence of phenanthroline. The varying bathochromic shifts for various $\mathrm{Cu}$ :Phen ratios show that copper-phenanthroline and copper-dye coordination are in competition. Copper binds most likely to nitrogen atoms of the dye, as it is observed on common blue dyes such as Direct Blue 86 or Reactive Blue 163. Consequently, the $\pi$-conjugation structure of the dye is modified, leading to a hypochromic effect in the visible range, resulting in partial color-stripping. It is also interesting to notice that the presence of a limited amount of phenanthroline (as in the 1:1 molar ratio) leads to better decolorizing than without or with an excess of phenanthroline. An explanation can be that a minimum of phenanthroline is necessary to solubilize copper and carry it in the dye environment, but an excess of phenanthroline in the copper sphere of coordination competes with dye coordination.

In conclusion, at $\mathrm{pH} 10.7$, one or several $\mathrm{Cu}$-Phen species would coordinate to the dye molecule via the $\mathrm{Cu}$ atom, since the latter can bind to the nitrogen lone pairs of an azo group. For instance, if $\mathrm{Cu}$ (Phen) $(\mathrm{OH})_{2}$ (the major species present, as calculated by PHREEQC) coordinates to the dye molecule, it would form a DR81-Cu-Phen-OH co-coordinate with total or partial release of the hydroxyl groups and/or phenanthroline ligand, depending on the Cu:Phen molar ratio.

The same trials were conducted at $\mathrm{pH} 12.3$ (dye in ionized state). The results are given in Figure 13. 


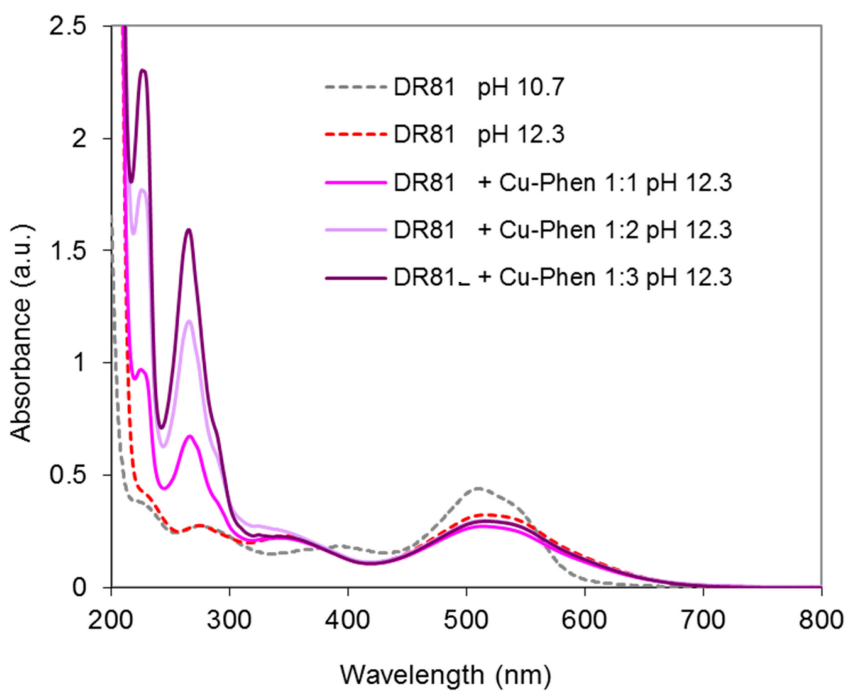

Figure 13. Absorbance spectra of the dye/copper-phenanthroline system at $\mathrm{pH}$ 12.3, with Cu:Phen molar ratio=1:1, 1:2 and 1:3, DR81:Cu molar ratio=1:1.5, and [DR81] $=10 \mu \mathrm{M}$, compared to the dye alone at $\mathrm{pH} 10.7$ and 12.3 .

At $\mathrm{pH}$ 12.3, a hypochromic effect of lower magnitude was observed when adding $\mathrm{Cu}$-Phen in the dye solution, by comparison to $\mathrm{pH} 10.7$ (Figure 12). Again, this effect can be attributed to the complexation of copper with the dye in its ionized form. The weakest effect ( $9 \%$ absorbance decay) was observed for 1:2 and 1:3 Cu:Phen molar ratios (superimposed curves), of the same magnitude as with copper alone $\left(\mathrm{CuSO}_{4}\right)$. Again at a $\mathrm{Cu}$ :Phen ratio of 1:1, complexation was more effective (17\% absorbance decay). The same reasons as for $\mathrm{pH} 10.7$ can be invoked.

The fact that dye color-stripping by $\mathrm{Cu}$-Phen was more efficient when the dye was unionized may also be explained by the speciation calculations presented in Table 1. At $\mathrm{pH}$ 12.3, more hydroxylated copper species $\left(\mathrm{Cu}(\mathrm{OH})_{3}{ }^{-}, \mathrm{Cu}(\mathrm{OH})_{4}{ }^{2-}\right.$, non-coordinated to phenanthroline) and more free phenanthroline are found, compared to $\mathrm{pH}$ 10.7, especially at a $\mathrm{Cu}$ :Phen ratio of 1:1. For the other $\mathrm{Cu}:$ Phen ratios, the amount of $\mathrm{Cu}(\mathrm{Phen})(\mathrm{OH})_{2}$ increases more significantly.

Overall, the results reveal better "color-stripping" effect at $\mathrm{pH} 10.7$ than at $\mathrm{pH}$ 12.3, when the dye is unionized and copper less hydroxylated, inducing less competition for dye complexation in the copper coordination sphere. More, to "decolorize" the dye solution, $\mathrm{CuSO}_{4}$ was found as effective as $\mathrm{Cu}$-Phen at molar ratios of 1:2 and 1:3, but less effective than $\mathrm{Cu}$-Phen at a molar ratio of 1:1. Thus, a minimum amount of phenanthroline appears necessary to ensure copper dissolution, but at the same time, it should not limit dye complexation too much.

Yet, for reproducible use, $\mathrm{Cu}$-Phen solutions at a molar ratio of 1:1 were found too unstable and molar ratios of 1:2 and 1:3 were used in the next experiments, where the effect of the dye:Cu-Phen ratio was investigated. Results for tested ratios varying between 2:1 and 2:3, at $\mathrm{pH} 10.7$ and 12.3, are presented in Figures 14 and 15. At pH 10.7 (unionized dye), increasing the amount of $\mathrm{Cu}$-Phen reduced significantly the dye absorbance, as a result of increased $\mathrm{Cu}$-dye complexation. Total discoloration was not reached in these conditions and the absorbance decay remained lower than $50 \%$. At pH 12.3 (ionized dye), the absorbance decrease was far less pronounced (almost inexistent). A Cu:Phen ratio of 1:3, not presented here, led to similar results.

As a summary, at $\mathrm{pH} 12.3$, copper complexation has almost no effect and the change of dye color from neutral to alkaline solutions may only be attributed to ionization of the naphthol group of the dye, leading to bathochromic-hypochromic effects. An opposite case is observed at $\mathrm{pH}$ 10.7, where coordination between copper and dye are responsible for discoloration. Therefore, the presence of hydroxide ions and phenanthroline in the coordination sphere of copper plays a central role in the observed color-stripping effect, also related to the ionization of the dye at alkaline $\mathrm{pH}$. 


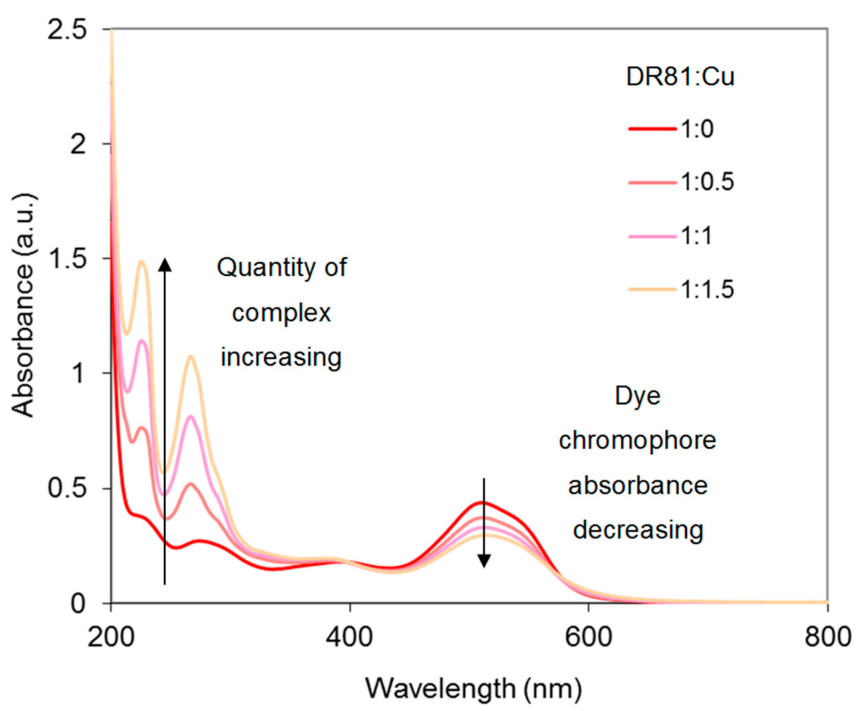

Figure 14. Absorbance spectra of the dye/copper-phenanthroline system at $\mathrm{pH}$ 10.7, with Cu:Phen molar ratio $=1: 2$ and $[\mathrm{DR} 81]=10 \mu \mathrm{M}$, for different DR81:Cu molar ratios.

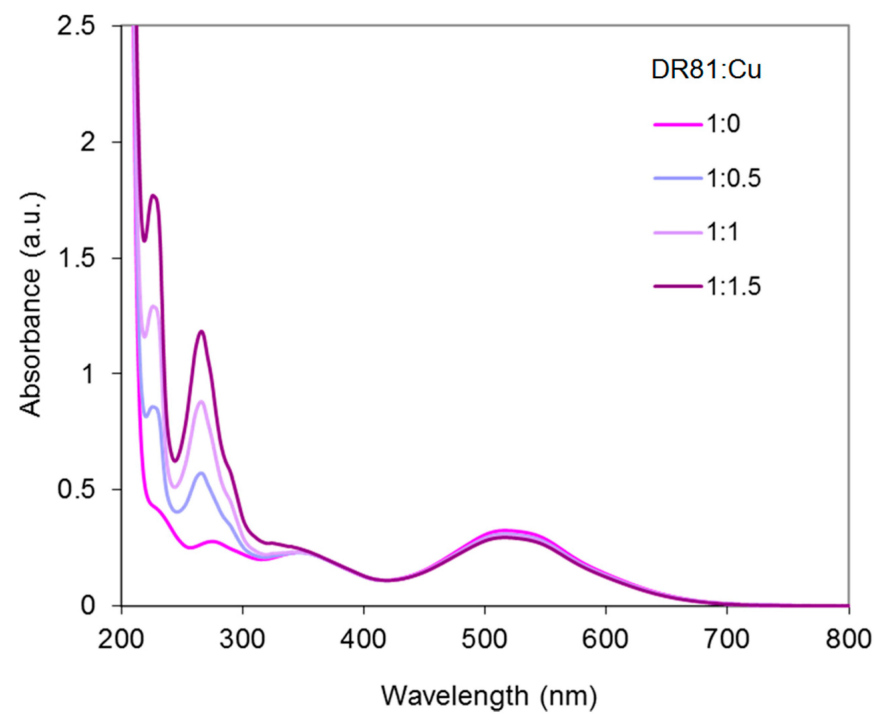

Figure 15. Absorbance spectra of the dye/copper-phenanthroline system at $\mathrm{pH}$ 12.3, with Cu:Phen molar ratio $=1: 2$ and $[\mathrm{DR} 81]=10 \mu \mathrm{M}$, for different DR81:Cu molar ratios.

\section{Results in Neutral Conditions}

Since the dye complexation with $\mathrm{Cu}$-Phen resulted in a stronger reduction of color in the case of $\mathrm{pH} 10.7$ compared to $\mathrm{pH} 12.3$, some tests were performed under near-neutral conditions, at $\mathrm{pH}$ 6.5. Controls were also carried out, excluding one component, before studying the complete three-component system (dye-Cu-Phen).

The first control test was a mixture of dye and $\mathrm{CuSO}_{4}$, in which case no precipitation occurred. Comparison with DR81 alone (results not presented) showed a very limited interaction between copper and dye. The second control was performed with pure phenanthroline. No interaction between the dye and phenanthroline occurred, as already seen at higher $\mathrm{pHs}$.

Before studying the UV-vis response of the three-component system, coordination between copper and phenanthroline at near-neutral $\mathrm{pH}$ was verified. The EPR spectra obtained from frozen solutions of $\mathrm{CuSO}_{4}$ and $\mathrm{Cu}$-Phen at $\mathrm{pH} 6.5$ are presented in Figure 16. 


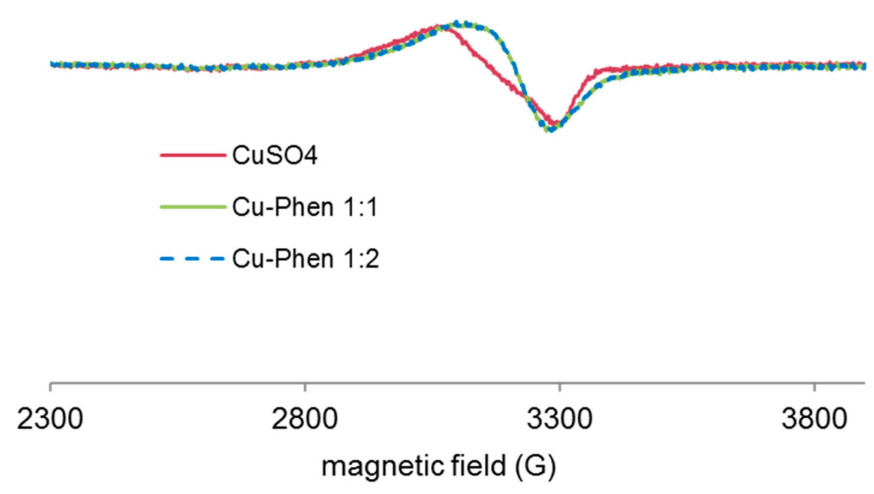

Figure 16. Experimental X-band EPR spectra recorded at $100 \mathrm{~K}$ in frozen aqueous solutions of $\mathrm{CuSO}_{4}$ and $\mathrm{Cu}$-Phen at $\mathrm{pH} 6.5$, with $\mathrm{Cu}:$ Phen molar ration $=1: 1$ and $1: 2$ and $[\mathrm{Cu}]=1.5 \mathrm{mM}$.

At $\mathrm{pH}$ 6.5, the Cu-Phen signal (at 1:1 or 1:2 Cu:Phen molar ratio) was clearly different from that of $\mathrm{CuSO}_{4}$ alone, evidencing copper-phenanthroline coordination. Besides, since both $\mathrm{Cu}$-Phen solutions exhibit the same signal (contrarily to the $\mathrm{Cu}$-Phen signals observed at $\mathrm{pH} 12.3$ in Figure 9), the major coordinates are the same in both cases. According to the speciation calculations by PHREEQC, with $[\mathrm{Cu}]=1.5 \mathrm{mM}, \mathrm{Cu}(\mathrm{Phen})^{2+}$ would be the major species when $\mathrm{Cu}$ :Phen $=1: 1$ and $\mathrm{Cu}(\mathrm{Phen})_{2}{ }^{2+}$ would replace most of it when Cu:Phen $=1: 2$. Consequently, it can be hypothesized that the EPR signature of copper is not much modified whether one or two phenanthroline ligands are attached to the copper atom.

Besides, it can be verified that the $\mathrm{CuSO}_{4}$ signal in Figure 16 was different from that observed at alkaline $\mathrm{pH}$ in Figure 9, as it did not exhibit the multiple peaks around $3300 \mathrm{G}$ attributed to copper hydroxylation. As a summary, it is experimentally verified here that $\mathrm{Cu}$-Phen complexes are different at neutral and alkaline $\mathrm{pH}$, as shown by the speciation calculations.

Figure 17 shows the UV-vis spectrum of the three-component system (Cu-Phen at 1:2 molar ratio) at $\mathrm{pH}$ 6.5. The absorbance of the dye is modified by the presence of $\mathrm{Cu}$-Phen. The pronounced red shift (from 510 to $516.5 \mathrm{~nm}$ ) and hypochromic effect (20\% intensity decrease) observed when adding Cu-Phen evidences coordination. However, the results are somewhat different from those obtained at $\mathrm{pH} 10.7$, where the dye is also unionized. These differences are probably due to the nature of the complexes, influenced by the copper environment at $\mathrm{pH} 6.5$, which is different from that at $\mathrm{pH} 10.7$, as shown by PHREEQC.

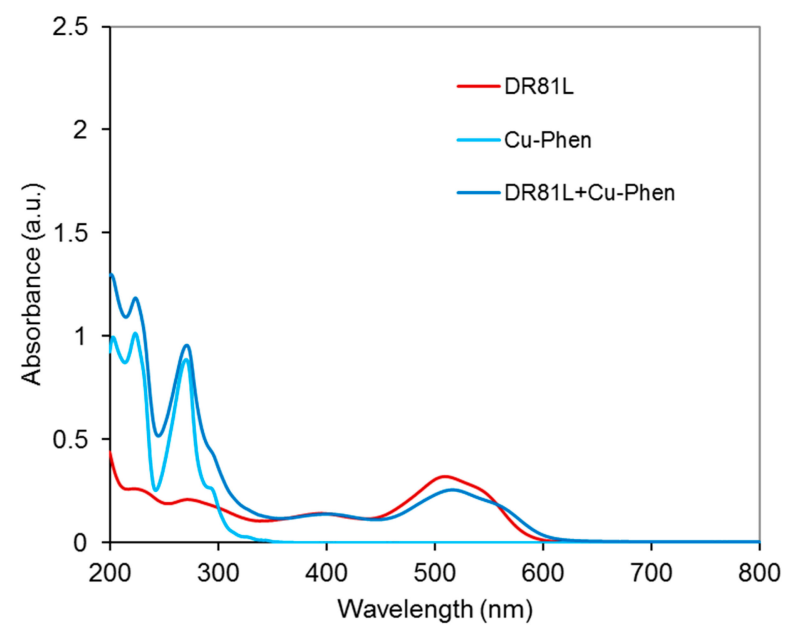

Figure 17. Absorbance spectrum of the dye/copper-phenanthroline system at $\mathrm{pH}$ 6.5, with Cu:Phen molar ratio = 1:2 and DR81:Cu molar ratio = 1:1.5, compared to the dye alone and copper-phenanthroline alone.

Finally, it appears that the most pronounced decrease of color was obtained at $\mathrm{pH} 10.7$, which seems to meet the optimal conditions for copper-dye coordination accompanied by color-stripping effect. 
At this step of the study, since UV-vis spectroscopy provided only limited information on changes of electronic structures of chromophores affected by coordination and solution environment, supplementary investigations were performed by EPR spectroscopy to study the occurrence of coordination.

\subsubsection{Proof of Dye-Cu-Phen Coordination}

EPR spectroscopy was used to study the chemical environment of copper(II), depending on the medium conditions. The analyses were conducted at $\mathrm{pH} 12.3$ (strong alkaline $\mathrm{pH}$ ), $\mathrm{pH} 10.7$ (ionization of the dye), and $\mathrm{pH} 6.5$ for a better comprehension of the occurring phenomena. Figures 18 and 19 display EPR spectra of $\mathrm{CuSO}_{4}$ with and without phenanthroline (Cu:Phen molar ratio = 1:2), and in the presence of DR81 or not, recorded at pH 12.3 (Figure 18) and pH 6.5 (Figure 19).

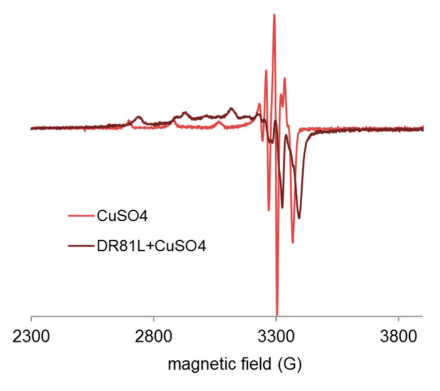

(a)

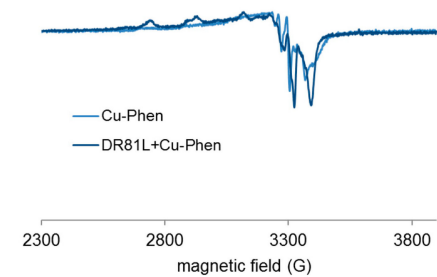

(b)

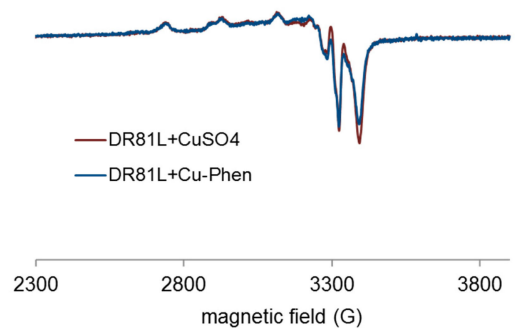

(c)

Figure 18. Experimental X-band EPR spectra recorded at $100 \mathrm{~K}$ in frozen aqueous solutions of (a) $\mathrm{CuSO}_{4}$ and $\mathrm{CuSO}_{4}+\mathrm{DR} 81$ (b) Cu-Phen and Cu-Phen + DR81 (c) $\mathrm{CuSO}_{4}+\mathrm{DR} 81$ and $\mathrm{Cu}-\mathrm{Phen}+\mathrm{DR} 81$, at pH 12.3, with $\mathrm{Cu}$ :Phen molar ratio $=1: 2$, DR81:Cu molar ratio $=1: 1.5$ and $[\mathrm{Cu}]=1.5 \mathrm{mM}$.

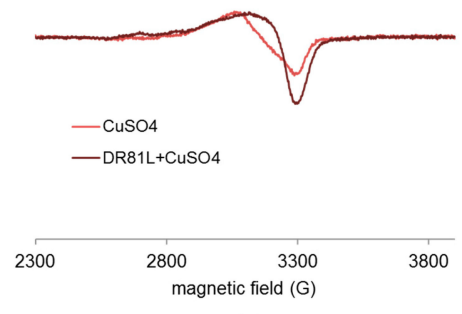

(a)
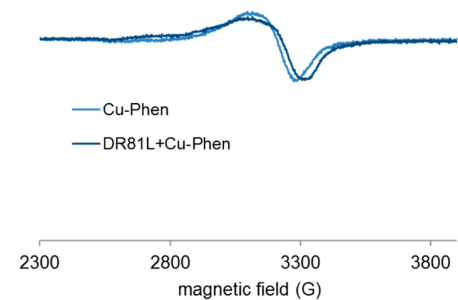

(b)

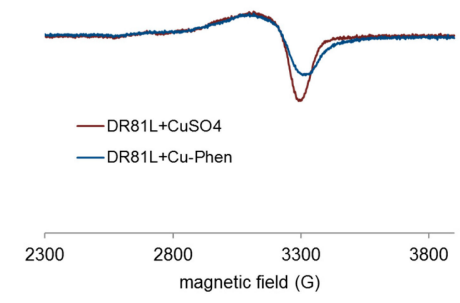

(c)

Figure 19. Experimental $X$-band EPR spectra recorded at $100 \mathrm{~K}$ in frozen aqueous solutions of (a) $\mathrm{CuSO}_{4}$ and $\mathrm{CuSO}_{4}+\mathrm{DR} 81$ (b) Cu-Phen and Cu-Phen + DR81 (c) $\mathrm{CuSO}_{4}+\mathrm{DR} 81$ and Cu-Phen + DR81, at pH 6.5, with Cu:Phen molar ratio $=1: 2$, DR81:Cu molar ratio $=1: 1.5$ and $[\mathrm{Cu}]=1.5 \mathrm{mM}$. 
At $\mathrm{pH}$ 12.3, the addition of DR81 notably modified the EPR spectrum of $\mathrm{CuSO}_{4}$ (Figure 18a), displaying different coupling constants and thus confirming the $\mathrm{Cu}$-dye coordination. In the same manner, Figure $18 \mathrm{~b}$ shows the $\mathrm{Cu}$-dye coordination in the presence of phenanthroline. Figure 18c shows that with or without phenanthroline, copper spectra in the presence of DR81 were absolutely similar and superimposed. This observation implies that the phenanthroline ligand has been fully eliminated and replaced by the dye in the coordination sphere of the copper ion. The affinity of copper towards the dye is thus higher than that towards phenanthroline.

According to the PHREEQC simulations (without dye), under these conditions, the major species at this $\mathrm{pH}$ in a 1:2 complex solution would be $\mathrm{Cu}(\mathrm{Phen})(\mathrm{OH})_{2}$. This means that in the presence of dye, one phenanthroline would be ejected to leave space for dye coordination. In the case of copper alone, the major species without dye would be $\mathrm{Cu}(\mathrm{OH})_{3}{ }^{-}$, one hydroxyl group of which can easily be exchanged with the dye molecule. However, such a modification of the copper environment hardly affected the dye chromophore structure, as it was seen in the corresponding UV-visible spectrum of Figure 10.

Figure 19 displays the results obtained at near-neutral $\mathrm{pH}$ (6.5). At this $\mathrm{pH}, \mathrm{CuSO}_{4}$ and $\mathrm{Cu}-\mathrm{Phen}$ solutions displayed different EPR spectra. These spectra also differed from those recorded at $\mathrm{pH} 12.3$. Different complexes are present depending on the $\mathrm{pH}$, as predicted by PHREEQC. In the case of $\mathrm{CuSO}_{4}$ (Figure 19a), the addition of DR81 led to the appearance of a new EPR signature. This signature probably corresponds to a mixture of a majority of $\mathrm{CuSO}_{4}$ and some $\mathrm{Cu}$-dye complex, as the hyperfine structure was not quite visible. A similar effect was observed in the case of $\mathrm{Cu}$-Phen (Figure 19b), with a new signature probably due to a mixture of $\mathrm{Cu}$-Phen and some $\mathrm{Cu}$-dye complex. Although rather comparable, the signals of Figure $19 \mathrm{c}$ are not fully superimposed, contrarily to the equivalent signals at $\mathrm{pH} 12.3$ (Figure 18c). Again, it is shown that the dye interacts strongly with copper(II). The small difference between the signals of Figure 19c is attributed to the presence of some phenanthroline in the coordination sphere of the copper ion (with $\mathrm{Cu}$-Phen), which differs from the case at $\mathrm{pH}$ 12.3. At $\mathrm{pH}$ 6.5, speciation indicates that the major species with a 1:2 $\mathrm{Cu}$ :Phen molar ratio would be $\mathrm{Cu}(\mathrm{Phen})_{2}{ }^{2+}$, as compared to $\mathrm{Cu}$ (Phen) $(\mathrm{OH})_{2}$ at $\mathrm{pH}$ 12.3. Therefore, an average of 2 phenanthroline ligands should be present around the copper atom in a Cu-Phen solution of $1.5 \mathrm{mM}$ at pH 6.5. Hence, it seems unlikely that both phenanthroline ligands would be ejected to be replaced by the dye, which would easily explain the differences between the DR81 $+\mathrm{CuSO}_{4}$ and DR81 + Cu-Phen spectra.

When mixing DR81 to Cu-Phen, the best "color-stripping" results were obtained at $\mathrm{pH} 10.7$. Therefore, it was interesting to perform a few EPR analyses at this $\mathrm{pH}$, in order to check whether the dye-Cu-Phen coordination was enhanced. If so, it could be owing to speciation differences or to the non-ionized state of the dye at that $\mathrm{pH}$.

Frozen solutions of $\mathrm{Cu}$-Phen and $\mathrm{Cu}$-Phen + DR81 were thus analyzed at $\mathrm{pH} 10.7$, as shown in Figure 20. Figure 20 shows that coordination also occurred at $\mathrm{pH} 10.7$. The signals were different from those at $\mathrm{pH} 12.3$ and 6.5, suggesting again a different mixture of coordinates. This is quite logical since the PHREEQC simulation gave the $\mathrm{Cu}(\mathrm{Phen})_{3}{ }^{2+}$ complex as the major species at $\mathrm{pH} 10.7$ $(45 \%$ of total $\mathrm{Cu})$, with a relatively high amount of $\mathrm{Cu}(\mathrm{Phen})(\mathrm{OH})_{2}$ as well $(34 \%)$.

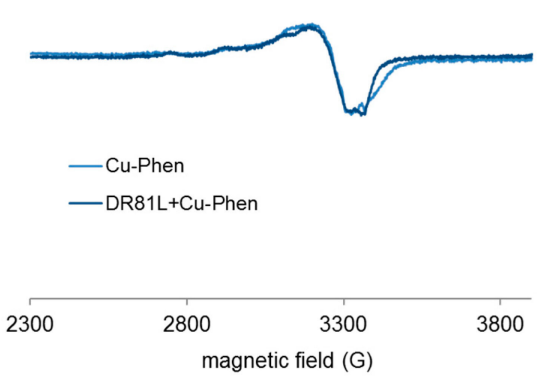

Figure 20. Experimental $\mathrm{X}$-band EPR spectra recorded at $100 \mathrm{~K}$ in frozen aqueous solutions of $\mathrm{Cu}$-Phen and Cu-Phen + DR81 at pH 10.7, with Cu:Phen molar ratio = 1:2, DR81:Cu molar ratio = 1:1.5 and [Cu] $=1.5 \mathrm{mM}$. 
In order to better understand the effect of dye addition to the copper sulfate or copper-phenanthroline solution, an excess of dye was tested: DR81:Cu molar ratio $=$ 10:1.5 instead of 1:1.5. The results at $\mathrm{pH} 12.3$ are presented in Figure 21.

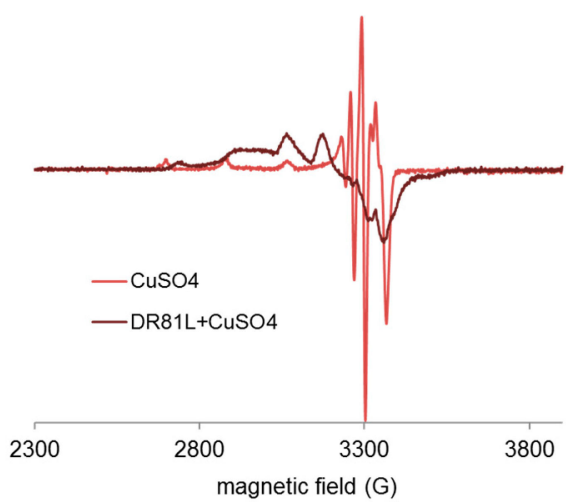

(a)

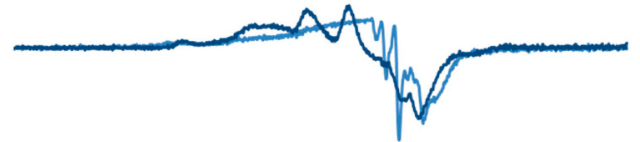

- Cu-Phen

-DR81L+Cu-Phen

$\begin{array}{rrr}2300 & 3300 & 3800 \\ & & \end{array}$

(b)

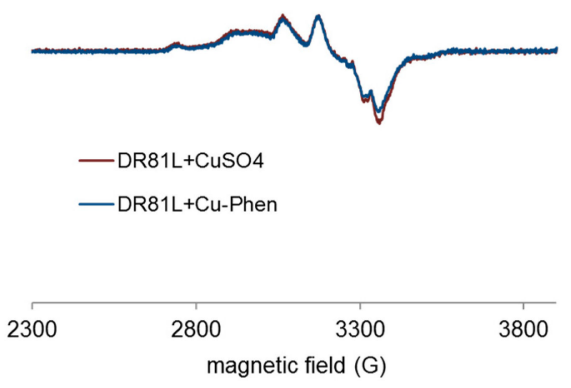

(c)

Figure 21. Experimental X-band EPR spectra recorded at $100 \mathrm{~K}$ in frozen aqueous solutions of (a) $\mathrm{CuSO}_{4}$ and $\mathrm{CuSO}_{4}+\mathrm{DR} 81$ (b) $\mathrm{Cu}$-Phen and $\mathrm{Cu}$-Phen + DR81 (c) $\mathrm{CuSO}_{4}+\mathrm{DR} 81$ and $\mathrm{Cu}-\mathrm{Phen}+\mathrm{DR} 81$, at pH 12.3, with $\mathrm{Cu}:$ Phen molar ratio $=1: 2$, DR81:Cu molar ratio $=10: 1.5$ and $[\mathrm{Cu}]=1.5 \mathrm{mM}$.

Using an excess of dye, the addition of DR81 clearly structured copper's environment, as the hyperfine structure is markedly visible in both cases ( $\mathrm{Cu}$ in Figure 21a and $\mathrm{Cu}-\mathrm{Phen}$ in Figure 21b). However, as well as with a lower amount of dye, Figure 21c shows that phenanthroline was ejected from copper's environment in the presence of DR81: the same Cu-dye coordinate was formed in both cases. According to the signature, it was certainly a mixture of coordinates. However, this signature does not seem to exhibit the hyperfine coupling constants of $\mathrm{CuSO}_{4}$ or $\mathrm{Cu}$-Phen. Therefore, most of the copper was probably bonded to the dye.The same experiment was repeated at pH 6.5 with an excess of DR81 (Figure 22).

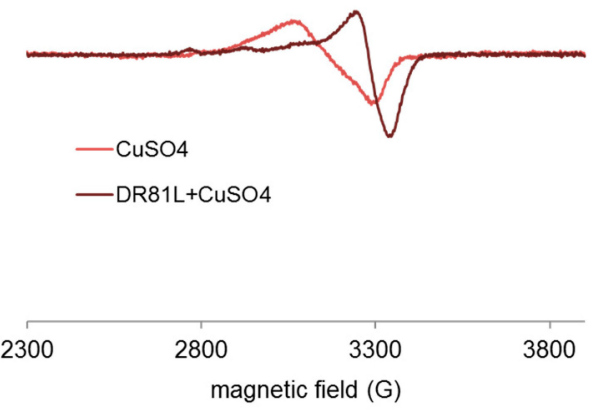

(a)

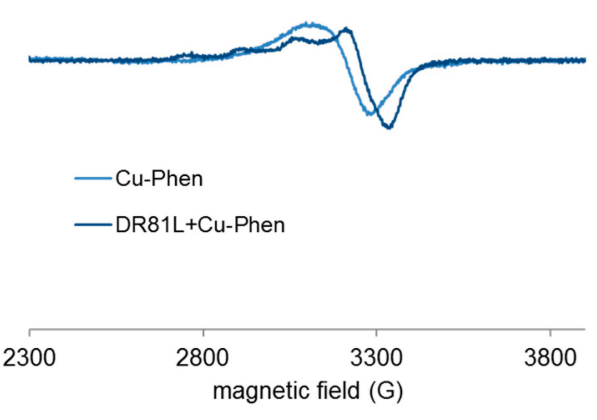

(b)

Figure 22. Cont. 


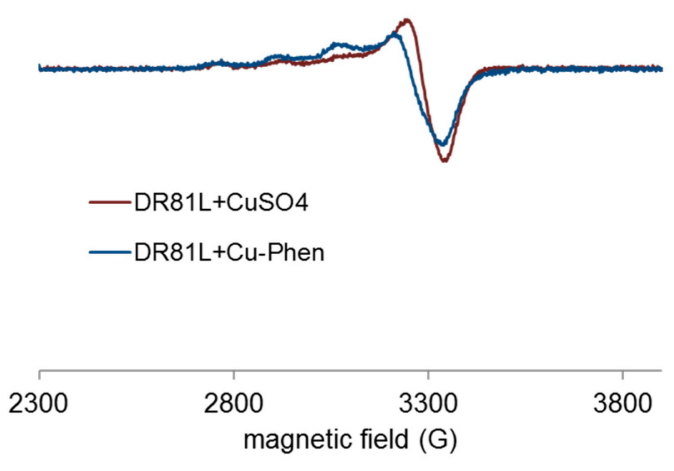

(c)

Figure 22. Experimental X-band EPR spectra recorded at $100 \mathrm{~K}$ in frozen aqueous solutions of (a) $\mathrm{CuSO}_{4}$ and $\mathrm{CuSO}_{4}+\mathrm{DR} 81$ (b) $\mathrm{Cu}$-Phen and Cu-Phen + DR81 (c) $\mathrm{CuSO}_{4}+\mathrm{DR} 81$ and Cu-Phen + DR81, at pH 6.5, with Cu:Phen molar ratio $=1: 2$, DR81: Cu molar ratio $=10: 1.5$ and $[\mathrm{Cu}]=1.5 \mathrm{mM}$.

At $\mathrm{pH}$ 6.5, again, the structuration of copper when adding DR81 was more noticeable than with a lower amount of dye. This confirms the coordinating effect between copper and DR81 also in near-neutral medium. Besides, as well as with DR81:Cu =1:1.5, Figure 22c exhibits two different spectra. The DR81-CuSO 4 mixture was thus different from the DR81-Cu-Phen mixture: phenanthroline was not fully replaced by the dye in copper's coordination sphere in the second case. Finally, the coordination effect was more important with an excess of dye but the differences depending on the $\mathrm{pH}$ did not vary.

All these results, in which phenanthroline would not or only partly be coordinated to the copper-dye complex, corroborate the previous UV-visible spectroscopic observation, as similar "color-stripping" was observed with either $\mathrm{CuSO}_{4}$ or Cu-Phen, at both $\mathrm{pH} 10.7$ (strong effect) and pH 12.3 (weak effect). At pH 6.5, however, $\mathrm{Cu}$-Phen seemed to have a more intense hypochromic effect on the dye than $\mathrm{CuSO}_{4}$ alone. This is most likely due to the formation of a Phen-Cu-dye co-coordinate in the first case.

As the "color-stripping" effect was much higher at $\mathrm{pH}$ 10.7, it can be assumed that complexation has more or less influence on the chromophore structure of the dye. Moreover, it probably also depends on the involved coordinates and on the $\mathrm{pH}$.

Actually, two cases can be distinguished:

(1) In strong alkaline conditions (ionized dye at $\mathrm{pH}$ 12.3) and at near neutral $\mathrm{pH}$ (unionized dye, $\mathrm{pH}$ 6.5), with or without phenanthroline, the chromophore's electronic structure was hardly affected by copper complexation.

(2) In medium alkaline conditions, $\mathrm{pH} 10.7$ (unionized dye), with or without phenanthroline, the chromophore structure was partly modified.

The EPR results also showed that the geometry around the copper ion varied as a function of $\mathrm{pH}$ for all three species, i.e., $\mathrm{CuSO}_{4}, \mathrm{Cu}$-Phen and $\mathrm{Cu}$-DR81. Besides, at near-neutral $\mathrm{pH}$, some phenanthroline remained in the coordination sphere of copper, probably owing to the presence of some Phen-Cu-DR81 complex.

\section{Materials and Methods}

\subsection{Raw Materials}

The direct azo dye Carta Red 8 BL liquid (C.I. Direct Red 81, 16\% w/w), DR81, was provided by Archroma (Reinach, Switzerland). Commercial chemical products of analytical or reagent grade were used: $\mathrm{NaOH}$ (99\%, reagent grade, Carl Roth, Karlsruhe, Germany), $\mathrm{H}_{2} \mathrm{O}_{2}\left(35 \%\right.$, Carl Roth), $\mathrm{CuSO}_{4} \cdot 5 \mathrm{H}_{2} \mathrm{O}$ (98.0\%, ACS reagent, Sigma Aldrich, now Merck, Darmstadt, Germany), 1,10-phenanthroline $(99.0 \%$, Acros Organics, Geel, Belgium). 


\subsection{Stock Solution Preparation}

The solvent was ultrapure water, degassed using a slight flow of nitrogen gas. The dye was diluted at a concentration of $400 \mu \mathrm{M}$ taking into account the concentration of the dye solution given by the supplier. The $\mathrm{Cu}$-Phen stock solution was composed of 1,10-phenanthroline and copper-sulfate: 1,10-phenanthroline was first ultrasonically solubilized, after what $\mathrm{CuSO}_{4} \cdot 5 \mathrm{H}_{2} \mathrm{O}$ was added to obtain a complex concentration of $5 \mathrm{mM}$. The initial $\mathrm{Cu}$ :Phen molar ratio was either 1:1, 1:2 or 1:3. Considering that most of the copper was coordinated, the complex concentration was calculated as being equal to the copper concentration. The controls were prepared according to the same procedure, without phenanthroline in the case of $\mathrm{CuSO}_{4}$ alone and without $\mathrm{CuSO}_{4} \cdot 5 \mathrm{H}_{2} \mathrm{O}$ in the case of phenanthroline alone.

\subsection{Reactions}

The reactions were performed with an initial dye concentration of $10 \mu \mathrm{M}$ at room temperature $\left(25^{\circ} \mathrm{C} \pm 2\right) .1 \mu$ mole of dye was mixed with the desired additives to obtain a final volume of $100 \mathrm{~mL}$, in the following order: degassed ultrapure water; dye; $\mathrm{NaOH} 1 \mathrm{M}$ or diluted $\mathrm{H}_{2} \mathrm{SO}_{4} ; \mathrm{CuSO}_{4} \cdot 5 \mathrm{H}_{2} \mathrm{O}$, Phen or $\mathrm{Cu}$-Phen; $\mathrm{H}_{2} \mathrm{O}_{2}$. A flow of nitrogen was then blown during approximately $30 \mathrm{~s}$ on the surface of the solution and the top of the beaker was sealed before $5 \mathrm{~min}$ of magnetic stirring. A sample of this solution was immediately analyzed by UV-vis spectroscopy.

The stoichiometry between $\mathrm{Cu}$-Phen and the dye varied from 0.5 to 1.5 since 1 mole of complex was assumed to be able to coordinate to 1 mole of dye.

The $\mathrm{pH}$ of each solution was checked before reaction on a duplicate solution to avoid any pollution or air-induced oxidation of the sample to be analyzed. The final $\mathrm{pH}$ of the remaining solution was measured during the spectrum acquisition. It was set to 10.7 and 12.3 (alkaline and high alkaline conditions) thanks to addition of $\mathrm{NaOH} 1 \mathrm{M}$ and some experiments required the addition of lower amounts of $\mathrm{NaOH}$ or diluted $\mathrm{H}_{2} \mathrm{SO}_{4}$ in order to obtain the desired $\mathrm{pH}$. No significant deviation was observed between the initial and final $\mathrm{pH}$.

The same protocol was applied for scientific control with the dye and copper-phenanthroline solutions alone, also analyzed by UV-vis spectroscopy.

\subsection{Centrifugation}

In case of precipitation, the samples were centrifuged with a 3-16P laboratory centrifuge (Sigma, Osterode am Harz, Germany) in order to further analyze the supernatant by UV-vis spectroscopy. The parameters were set between 3000 and $4000 \mathrm{rpm}$ with a relative centrifuge force of 1730 to $3076 \times \mathrm{g}$.

\subsection{UV-Vis Spectroscopy}

The color variation of the dye solution was followed by UV-vis spectroscopy. The absorbance spectra were recorded from 200 to $800 \mathrm{~nm}$ on a UV-1800 UV-vis spectrophotometer (Shimadzu, Kyoto, Japan). When necessary, the samples were centrifuged beforehand. In accordance with Beer-Lambert law, the dye concentration was proportional to its absorbance at its maximum absorption wavelength. Several replicates were analyzed to verify the reproducibility of the measurements, which was useful to evaluate whether differences between two results were significant.

\subsection{EPR Spectroscopy}

Since they exhibit a $\mathrm{d}^{9}$ configuration, $\mathrm{Cu}(\mathrm{II})$ and its coordinates are paramagnetic species. These give a typical EPR signal depending on the coordination geometry.

X-band EPR spectra were recorded at $100 \mathrm{~K}$ with an EMX Plus spectrometer (Bruker, Billerica, MA, USA) equipped with an ER-4131 VT Bruker cavity for liquid nitrogen experiments. Indeed, these EPR analyses were conducted on frozen samples. This allows to obtain a random collection of paramagnets and to improve the spectrum resolution. 
The instrument settings were the following: receiver gain $30 \mathrm{~dB}$, modulation amplitude $4 \mathrm{G}$, attenuation $10 \mathrm{~dB}$. The tested samples were aqueous solutions of $\mathrm{CuSO}_{4}$ and $\mathrm{Cu}$-Phen, with or without DR81, and with or without sodium hydroxide, leading to $\mathrm{pH} 12.3-12.5$ or $\mathrm{pH} 6.5-7$, respectively. The concentrations were the following: $1 \mathrm{mM} \mathrm{DR} 81,1.5 \mathrm{mM} \mathrm{CuSO}_{4} \cdot 5 \mathrm{H}_{2} \mathrm{O}$, and Cu:Phen molar ratio $=1: 2$.

\section{Conclusions}

In conclusion, the results showed that whatever the $\mathrm{pH}$, the addition of $\mathrm{Cu}$-Phen complexes can reduce the color of a Direct Red 81 aqueous solution. This apparent color-stripping effect would be due to the coordination of copper with the dye after total or partial release of the phenanthroline ligand, which was evidenced by EPR spectroscopy. Interestingly, at pH 6.5, some phenanthroline remained in the coordination sphere of copper, whereas at alkaline $\mathrm{pH}$, it seemed to be ejected.

The complexation of copper with Direct Red 81 is certainly responsible for the decrease of its absorbance in the visible range, up to 50\% color-stripping depending on the $\mathrm{pH}$, under the concentration conditions used, although this absorbance could not be totally cancelled. This phenomenon seemed to be strongly correlated with the nature of the $\mathrm{Cu}$-Phen species which in turn are dependent on the $\mathrm{pH}$. The best color-stripping results were obtained at medium alkalinity ( $\mathrm{pH}$ 10.7), with the $\mathrm{Cu}(\mathrm{Phen})(\mathrm{OH})_{2}$ species, leading to a hydroxylated dye-copper complex after phenanthroline ejection.

The dye-complexing effect of $\mathrm{Cu}$-Phen species may be interesting for dye effluent treatment, especially in case of already alkaline effluents. It might be used as an alternative to physicochemical techniques, such as chemical oxidation, chemical reduction, adsorption or light-illumination treatments, to decolorize colored wastewaters.

Acknowledgments: LGP2 is part of the LabEx Tec 21 (Investissements d'Avenir-grant agreement No. ANR-11-LABX-0030) and of PolyNat Carnot Institute (Investissements d'Avenir-grant agreement No. ANR-16-CARN-0025-01). This research was made possible thanks to the facilities of the TekLiCell platform funded by the Région Rhône-Alpes (ERDF: European regional development fund) and to the EPR facilities of CNRS's research infrastructure RENARD (IR-RPE CNRS 3443). The authors thank Patrice Nortier for introducing E.W. and G.M. to the PhreeQC software. Carole Duboc is also warmly thanked for proposing to use the EPR facilities of the DCM laboratory and for her advice as an EPR expert.

Author Contributions: E.W., N.M. and G.M. conceived and designed the experiments; E.W. performed the experiments, with the help of F.M. to run the EPR spectrometer and record the results; E.W. analyzed the data; E.W. wrote the paper, N.M. and G.M. reviewed the paper.

Conflicts of Interest: The authors declare no conflict of interest. The founding sponsors had no role in the design of the study; in the collection, analyses, or interpretation of data; in the writing of the manuscript, and in the decision to publish the results.

\section{References}

1. Alén, R. Papermaking additives. In Papermaking Science and Technology: Vol. 4. Papermaking Chemistry; Papermaking science and technology; Fapet Oy: Helsinki, Finland, 2007; ISBN 978-952-5216-24-0.

2. Göttsching, L.; Pakarinen, H. Papermaking Science and Technology: Vol. 7. Recycled Fiber and Deinking; Papermaking Science and Technology; Fapet Oy: Helsinki, Finland, 2000; Volume 7, ISBN 978-95-2-521607-1.

3. Blau, F. Über neue organische Metallverbindungen. Monatschefte Chem. Verwandte Teile Anderer Wiss. 1898, 19, 647-689. [CrossRef]

4. Sigman, D.S.; Graham, D.R.; D'Aurora, V.; Stern, A.M. Oxygen-dependent cleavage of DNA by the 1,10-phenanthroline cuprous complex. Inhibition of Escherichia coli DNA polymerase I. J. Biol. Chem. 1979, 254, 12269-12272. [PubMed]

5. Sigman, D.S. Nuclease activity of 1,10-phenanthroline-copper ion. Acc. Chem. Res. 1986, 19, $180-186$. [CrossRef]

6. Thederahn, T.B.; Kuwabara, M.D.; Larsen, T.A.; Sigman, D.S. Nuclease activity of 1,10-phenanthroline-copper: Kinetic mechanism. J. Am. Chem. Soc. 1989, 111, 4941-4946. [CrossRef]

7. Lu, L.-P.; Zhu, M.-L.; Yang, P. Crystal structure and nuclease activity of mono(1,10-phenanthroline) copper complex. J. Inorg. Biochem. 2003, 95, 31-36. [CrossRef] 
8. Coucharriere, C. Mise au Point et Etude d'un Système D'activation du Peroxyde D'hydrogène en Délignification et Blanchiment des Pâtes Chimiques. Ph.D. Thesis, University of Grenoble, Grenoble, France, 2000.

9. Marlin, N.; Coucharriere, C.; Mortha, G.; Lachenal, D.; Larnicol, P.; Hostachy, J.C. Use of o-phenanthroline as a catalyst in hydrogen peroxide stages. In Proceedings of the 13th International Symposium on Wood Fibre and Pulping Chemistry, Auckland, New Zealand, 16-19 May 2005; APPITA: Carlton, Australia, 2005; pp. 29-34.

10. Vladut, N.I. Système Chimique Délignifiant à Base de Peroxyde D’hydrogène. Ph.D. Thesis, University of Grenoble, Grenoble, France, 2012.

11. Cabanne, L.; Larnicol, P.; Coucharriere, C. Hydrogen Peroxide Activation in Delignification and Bleaching of Wood Pulp Using a Phenanthroline-Copper Complex. WO03080925 (A1), 2 October 2003.

12. Blanc, J.; Calais, C.; Dubois, J.L. Process for Delignification and Bleaching of Paper Pulp Using Activated Hydrogen Peroxide. WO02012028800 (A1), 28 June 2012.

13. Korpi, H.; Lahtinen, P.; Sippola, V.; Krause, O.; Leskelä, M.; Repo, T. An efficient method to investigate metal-ligand combinations for oxygen bleaching. Appl. Catal. A Gen. 2004, 268, 199-206. [CrossRef]

14. Korpi, H.; Figiel, P.J.; Lankinen, E.; Ryan, P.; Leskelä, M.; Repo, T. On in situ prepared Cu-Phenanthroline complexes in aqueous alkaline solutions and their use in the catalytic oxidation of veratryl alcohol. Eur. J. Inorg. Chem. 2007, 2007, 2465-2471. [CrossRef]

15. Lahtinen, P.; Korpi, H.; Haavisto, E.; Leskelä, M.; Repo, T. Parallel screening of homogeneous copper catalysts for the oxidation of benzylic alcohols with molecular oxygen in aqueous solutions. J. Comb. Chem. 2004, 6, 967-973. [CrossRef] [PubMed]

16. Korpi, H. Copper di-Imine Complexes: Structures and Catalytic Activity in the Oxidation of Alcohols by Dioxygen. Ph.D. Thesis, University of Helsinki, Helsinki, Finland, 2005.

17. Sippola, V.O.; Krause, A.O.I. Bis(o-phenanthroline)copper-catalysed oxidation of lignin model compounds for oxygen bleaching of pulp. Catal. Today 2005, 100, 237-242. [CrossRef]

18. Alderighi, L.; Gans, P.; Ienco, A.; Peters, D.; Sabatini, A.; Vacca, A. Hyperquad simulation and speciation (HySS): A utility program for the investigation of equilibria involving soluble and partially soluble species. Coord. Chem. Rev. 1999, 184, 311-318. [CrossRef]

19. Marlin, N.; Fernandes, J.; Benattar, N. New ways to improve color-stripping of deinked pulps and dyed effluents. In Proceedings of the 14th International Symposium on Wood Fibre and Pulping Chemistry, Durban, South Africa, 25-28 June 2007; TAPPSA: Kloof, South Africa, 2007.

20. Walger, E.; Rivollier, C.; Marlin, N.; Mortha, G. Activated $\mathrm{H}_{2} \mathrm{O}_{2}$ discoloration of a model azoic dye-colored pulp. In Proceedings of the 13th European Workshop on Lignocellulosics and Pulp, Seville, Spain, 24-27 June 2014; De Gruyter: Seville, Spain, 2014; pp. 863-866.

21. Sharpe, P.E.; Lowe, R.W. The bleaching of colored recycled fibers. In Proceedings of the 1993 Pulping Conference, Boston, MA, USA, 15-17 June 1993; TAPPI Press: Boston, MA, USA, 1993; Volume 3, pp. 1205-1217.

22. Walger, E. Study of the Activation of Hydrogen Peroxide by the Copper(II)-Phenanthroline Complex for the Color-Stripping of Recovered Cellulosic Fibers; Université Grenoble Alpes: Grenoble, France, 2016.

23. Moeller, T. Inorganic Chemistry: An Advanced Textbook; Wiley: New York, NY, USA, 1952.

24. Ringbom, A. Les Complexes en Chimie Analytique: Comment Choisir Rationnellement les Meilleures Méthodes D'analyse Complexométrique; Dunod: Paris, France, 1967.

25. Schilt, A.A. Analytical Applications of 1,10-Phenanthroline and Related Compounds, 1st ed.; International Series of Monographs in Analytical Chemistry; Pergamon Press: Oxford, UK; London, UK; Edinburgh, UK, 1969; Volume 32.

26. Smith, R.M.; Martell, A.E. Critical Stability Constants; Plenum Press: New York, NY, USA; London, UK, 1975; ISBN 0-306-35212-5.

27. Mcbryde, W.A.E. A Critical Review of Equilibrium Data for Proton and Metal Complexes of 1,10-Phenanthroline, 2,2'-Bipyridyl and Related Compounds; Pergamon Press: Oxford, UK; New York, NY, USA; Toronto, ON, Canada; Rushcutters Bay, Australia; Paris, France; Kronberg-Taunus, Germany, 1978; ISBN 0-08-022344-3.

28. Yamazaki, K.; Yokoi, H.; Sone, K. Spectrochemical studies on o-phenanthroline complex salts. J. Chem. Soc. Japan: Pure Chem. Sect. 1948, 69, 137-140. [CrossRef]

29. Armaroli, N.; De Cola, L.; Balzani, V.; Sauvage, J.-P.; Dietrich-Buchecker, C.O.; Kern, J.-M. Absorption and luminescence properties of 1,10-phenanthroline, 2,9-diphenyl-1,10-phenanthroline, 2,9-dianisyl-1,10-phenanthroline and their protonated forms in dichloromethane solution. J. Chem. Soc. Faraday Trans. 1992, 88, 553-556. [CrossRef] 
30. Vallee, B.L.; Rupley, J.A.; Coombs, T.L.; Neurath, H. The Role of Zinc in Carboxypeptidase. J. Biol. Chem. 1960, 235, 64-69.

31. Ni, Y.; Lin, D.; Kokot, S. Synchronous fluorescence, UV-visible spectrophotometric, and voltammetric studies of the competitive interaction of bis(1,10-phenanthroline)copper(II) complex and neutral red with DNA. Anal. Biochem. 2006, 352, 231-242. [CrossRef] [PubMed]

32. Bovet, C.; Barron, A.R. Electron Paramagnetic Resonance Spectroscopy of Copper(II) Compounds-OpenStax CNX. Available online: http://cnx.org/contents/NB5XiHcn@2/Electron-Paramagnetic-Resonanc (accessed on 17 May 2016).

Sample Availability: Samples of the compound Direct Red 81 are available from the authors.

(C) 2018 by the authors. Licensee MDPI, Basel, Switzerland. This article is an open access article distributed under the terms and conditions of the Creative Commons Attribution (CC BY) license (http:/ / creativecommons.org/licenses/by/4.0/). 